\title{
Report on FY 2020 Test Results in Support of the Development of EPP Plus SMT Design Method
}

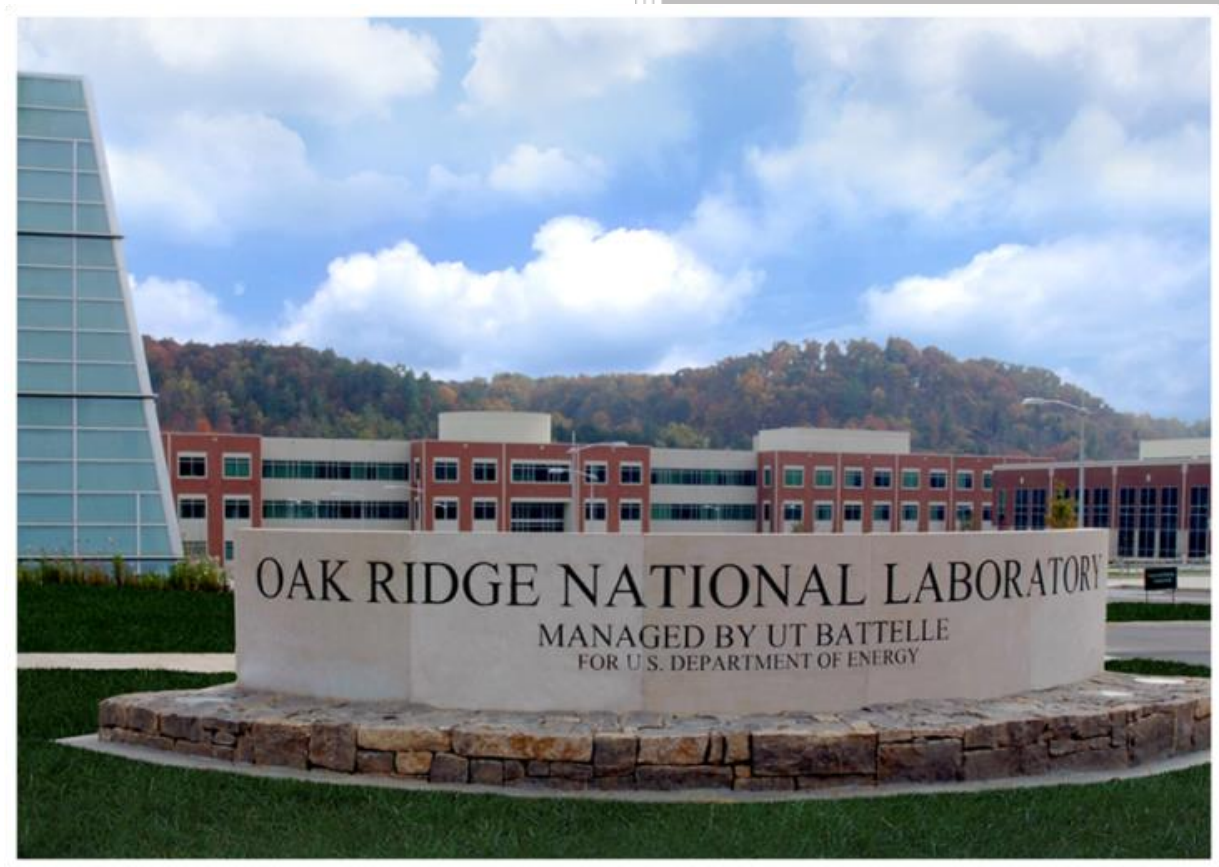

Approved for public release.

Distribution is unlimited.

Yanli Wang

Peijun Hou

Robert I. Jetter

T.-L. Sham

August 2020 


\title{
DOCUMENT AVAILABILITY
}

Reports produced after January 1, 1996, are generally available free via US Department of Energy (DOE) SciTech Connect.

Website www.osti.gov

Reports produced before January 1, 1996, may be purchased by members of the public from the following source:

\author{
National Technical Information Service \\ 5285 Port Royal Road \\ Springfield, VA 22161 \\ Telephone 703-605-6000 (1-800-553-6847) \\ TDD 703-487-4639 \\ Fax 703-605-6900 \\ E-mail info@ntis.gov \\ Website http://classic.ntis.gov/
}

Reports are available to DOE employees, DOE contractors, Energy Technology Data Exchange representatives, and International Nuclear Information System representatives from the following source:

Office of Scientific and Technical Information

PO Box 62

Oak Ridge, TN 37831

Telephone 865-576-8401

Fax 865-576-5728

E-mail reports@osti.gov

Website http://www.osti.gov/contact.html

This report was prepared as an account of work sponsored by an agency of the United States Government. Neither the United States Government nor any agency thereof, nor any of their employees, makes any warranty, express or implied, or assumes any legal liability or responsibility for the accuracy, completeness, or usefulness of any information, apparatus, product, or process disclosed, or represents that its use would not infringe privately owned rights. Reference herein to any specific commercial product, process, or service by trade name, trademark, manufacturer, or otherwise, does not necessarily constitute or imply its endorsement, recommendation, or favoring by the United States Government or any agency thereof. The views and opinions of authors expressed herein do not necessarily state or reflect those of the United States Government or any agency thereof. 
Materials Science and Technology Division

\title{
REPORT ON FY 2020 TEST RESULTS IN SUPPORT OF THE DEVELOPMENT OF EPP PLUS SMT DESIGN METHOD
}

\author{
Yanli Wang \\ Peijun Hou* \\ Robert I. Jetter** \\ T.-L. Sham
}

\footnotetext{
* University of Tennessee

** RI Jetter Consulting

$\dagger$ Argonne National Laboratory
}

Date Published: August 2020

\author{
Prepared by \\ OAK RIDGE NATIONAL LABORATORY \\ Oak Ridge, TN 37831-6283 \\ managed by \\ UT-BATTELLE, LLC \\ for the \\ US DEPARTMENT OF ENERGY \\ under contract DE-AC05-00OR22725
}





\section{CONTENTS}

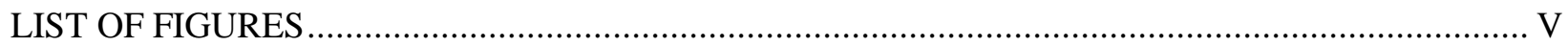

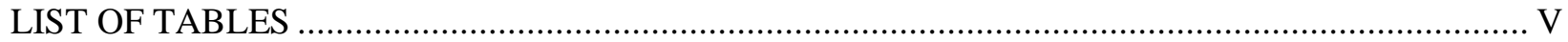

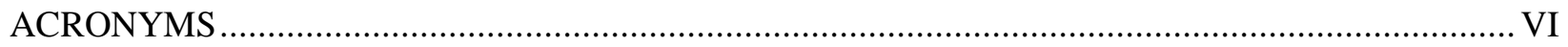

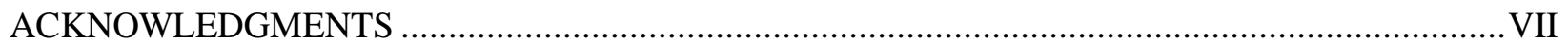

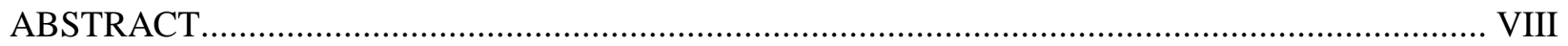

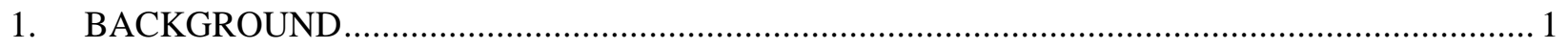

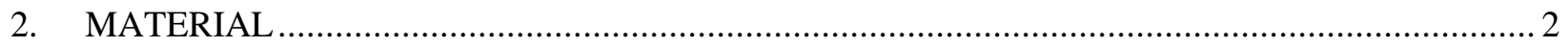

3. EFFECT OF PRIMARY PRESSURE LOAD ON SMT CREEP-FATIGUE LIFE

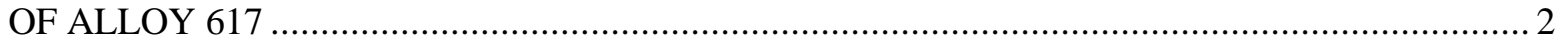

3.1 SUMMARY OF PREVIOUS PRESSURIZED SMT TEST RESULTS.............................. 3

3.2 EXTENSION OF SBSMT TECHNIQUE FOR EVALUATION OF THE EFFECT OF

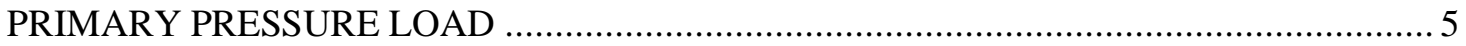

3.2.1 Effect of Internal Pressure on SBSMT with an Elastic Follow-up of 3.5 at $950^{\circ} \mathrm{C} \ldots \ldots .6$

3.2.2 Effect of Internal Pressure on SBSMT with an Elastic Follow up of 2 at $950^{\circ} \mathrm{C} \ldots \ldots . . .10$

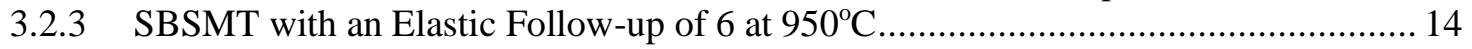

3.3 SUMMARY OF THE PRESSURIZED SBSMT RESULTS ON ALLOY $617 \ldots \ldots \ldots \ldots \ldots \ldots . . . . . . . . .17$

3.4 DISCUSSIONS ON THE EFFECT OF PRIMARY LOAD ON SMT CF LIFE................... 17

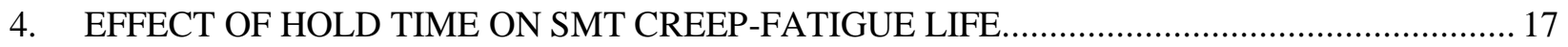

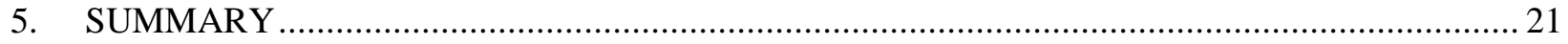

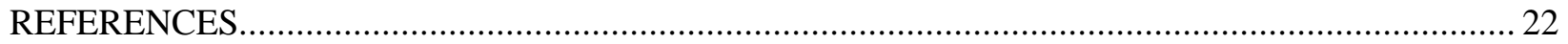




\section{LIST OF FIGURES}

Fig. 1. Pressurization SMT specimen and experimental setup..................................................... 3

Fig. 2. Axial stress-strain curve with elastic follow-up for the pressurized SMT ................................ 4

Fig. 3. Specimen geometry of pressurized SBSMT. Units are in inches............................................ 5

Fig. 4. Picture of the pressurized SBSMT Alloy 617 specimen...................................................... 6

Fig. 5. (a) Representative hysteresis loops and (b) elastic follow-up factor as a function of applied

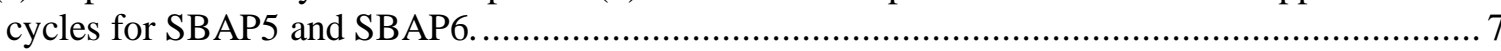

Fig. 6. Comparison of (a) maximum and minimum stresses, (b) strain ranges, and (c) maximum and minimum strains for SBAP5 and SBAP6 as a function of applied cycles............................ 8

Fig. 7. Characteristics of the hysteresis loop of the SBSMT test. ................................................... 9

Fig. 8. Comparison of stress histories of representative cycles for (a) SBAP5 and (b) SBAP6 and comparison of (c) the stress relaxation behavior during holding segment and (d) the loading strain ranges as a function of applied cycles ................................................................ 9

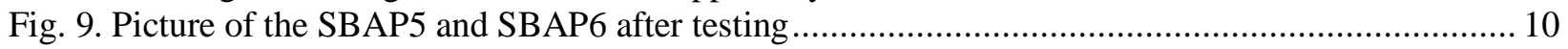

Fig. 10. (a) Representative hysteresis loops and (b) elastic follow-up factors as a function of

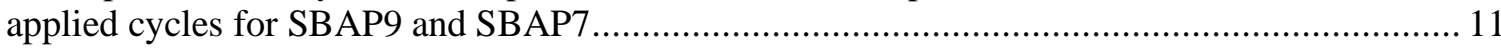

Fig. 11. Comparison of (a) maximum and minimum stresses, (b) strain ranges and (c) maximum and minimum strains as a function of applied cycles for SBAP9 and SBAP7 ......................... 12

Fig. 12. Comparison of the stress histories of representative cycles for (a) SBAP9 and (b) SBAP7 and comparison of (c) the stress relaxation behavior during holding segment and (d) the

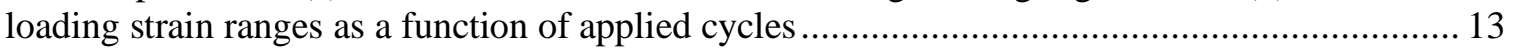

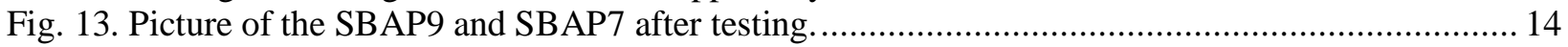

Fig. 14. (a) Representative hysteresis loops and (b) the elastic follow-up factors as a function of

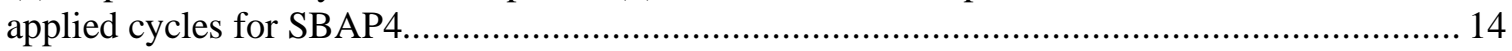

Fig. 15. (a) Maximum and minimum stresses, (b) strain ranges, and (c) maximum and minimum strains as a function of applied cycles for SBAP4.

Fig. 16. (a) Stress histories of the representative hysteresis loops, (b) the stresses during holding,

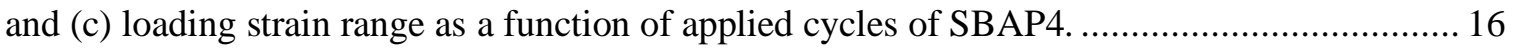

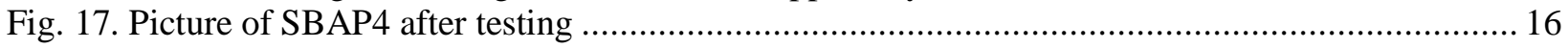

Fig. 18. Standard fatigue and CF data and modified Coffin model for Alloy 617 at $950^{\circ} \mathrm{C}$ with (a) $q=1.0$, (b) $q=2.0$, (c) $q=3.5$, and (d) predicted short hold time effect................................ 19

Fig. 19. Maximum and minimum stresses of strain-controlled pure fatigue test on Alloy 617 with $0.163 \%$ strain range at $950^{\circ} \mathrm{C}$.

Fig. 20. Comparison of the strain-controlled pure fatigue (PF) test with the corresponding fatigue data and the best-fit curve of Alloy 617 at $950^{\circ} \mathrm{C}$. 20

\section{LIST OF TABLES}

Table 1. Chemical compositions of Alloy 617 plate with heat number 314626 (weight \%) ..................... 2

Table 2. Results of previous pressurized SMT testing for Alloy 617 with 600 s tension hold ................... 4

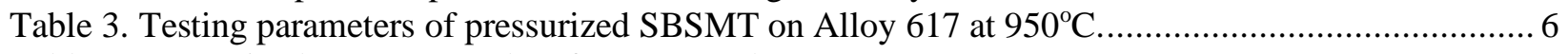

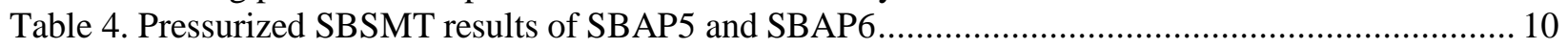

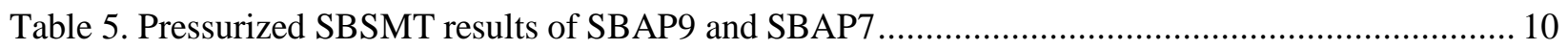

Table 6. Summary of the pressurized SBSMT on Alloy 617 with tension hold of $600 \mathrm{~s}$ at $950^{\circ} \mathrm{C} \ldots \ldots \ldots . . . .17$

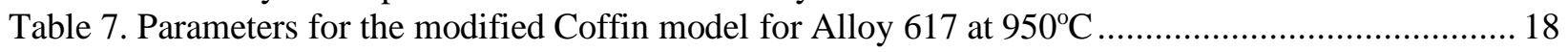

Table 8. Estimation of CF life and test duration using modified Coffin model for Alloy 617 at

$0.163 \%$ strain range and at $950^{\circ} \mathrm{C}$ 21 


\section{ACRONYMS}

$\begin{array}{ll}\text { ART } & \text { Advanced Reactor Technologies Program } \\ \text { ASME } & \text { American Society of Mechanical Engineers } \\ \text { B\&PV } & \text { Boiler and Pressure Vessel } \\ \text { CF } & \text { Creep-Fatigue } \\ \text { DOE } & \text { Department of Energy } \\ \text { EPP } & \text { Elastic-Perfectly Plastic } \\ \text { ORNL } & \text { Oak Ridge National Laboratory } \\ \text { SBSMT } & \text { Single-Bar Simplified Model Test } \\ \text { SMT } & \text { Simplified Model Test }\end{array}$




\section{ACKNOWLEDGMENTS}

This research was sponsored by the US Department of Energy, Office of Nuclear Energy, under contract DE-AC05-00OR22725 with Oak Ridge National Laboratory (ORNL), managed and operated by UTBattelle, LLC, and under contract No. DE-AC02-06CH1 1357 with Argonne National Laboratory, managed and operated by UChicago Argonne LLC. Programmatic direction was provided by the Office of Nuclear Reactor Deployment of the Office of Nuclear Energy.

The authors gratefully acknowledge the support provided by Sue Lesica, Federal Manager, Advanced Materials, Advanced Reactor Technologies (ART) Program, Diana Li, Federal Program Manager, ART Gas-Cooled Reactors (GCR) Campaign, and Gerhard Strydom of Idaho National Laboratory, National Technical Director, ART GCR Campaign.

The authors also wish to thank ORNL staff member C. Shane Hawkins for technical support and Edgar Lara-Curzio and Lianshan Lin for reviewing this report. 


\begin{abstract}
Experiments in support of the development of the integrated Elastic-Perfectly Plastic (EPP) analysis and Simplified Model Test (SMT) design methodology continued in FY 2020. The previously developed single-bar SMT (SBSMT) technique was successfully extended to tubular shaped Alloy 617 specimens for evaluation of the effect of primary pressure load on SMT creep-fatigue $(\mathrm{CF})$ properties at $950^{\circ} \mathrm{C}$. A series of pressurized SMT tests were performed with various elastic follow-up factors and strain ranges. The results show that the primary pressure load reduces the SMT CF cycles. The reduction of SMT CF life due to primary load was found to be dependent on strain ranges, elastic follow up and test temperatures. These results are crucial for verification of the EPP strain range analysis in the EPP+SMT evaluation procedure.

Additionally, hold time effect on the SMT CF life cycles is a determining factor for generating the $\mathrm{EPP}+\mathrm{SMT} \mathrm{CF}$ design curves. Lack of test data in the high cycle and low strain range region results in major uncertainty in developing the design curves. In FY2020, experiments were designed, and testing started on Alloy 617 at $950^{\circ} \mathrm{C}$ to fill the gap in experimental data. The on-going CF and additional SMT $\mathrm{CF}$ with elastic follow-up at low strain ranges will generate the information needed to verify the methods for extrapolation to long hold time and finalize the EPP+SMT design method.
\end{abstract}




\section{BACKGROUND}

Creep-fatigue at elevated temperatures is the most damaging structural failure mode. Significant efforts have been devoted to the elevated temperature code rule development in Section III, Division 5, Subsection HB Subpart B of the ASME Boiler and Pressure Vessel Code, in the past 40 years to ascertain conservative structural designs against creep-fatigue (CF) failure. The current Subsection HB Subpart B $\mathrm{CF}$ evaluation procedure was established by the steps of (1) analytically obtaining a detailed stress-strain history, (2) comparing the stress and strain components to cyclic test results and deconstructed into stress and strain quantities, and (3) recombining the results to obtain a damage function in the form of the socalled CF damage-diagram. The deconstruction and recombination present difficulties in evaluation of test data and determination of cyclic damage in design. The uncertainties in these steps lead to the use of overly conservative design factors in the current $\mathrm{CF}$ procedure.

The integrated Elastic-Perfectly Plastic (EPP) plus Simplified Model Test (SMT) design methodology, referred to as EPP+SMT method, is an alternative CF evaluation methodology. The concept is to incorporate the SMT CF test data-based approach into the EPP methodology to avoid separate evaluation of creep and fatigue damage. It greatly simplifies the evaluation procedure for elevated temperature cyclic service. In the SMT approach, a key point is that it no longer requires the damage interaction, or damagediagram, and the combined effects of creep and fatigue are accounted for in the SMT test data. The SMT specimens are designed to replicate or bound the stress and strain redistribution that occurs in actual components when loaded in the creep regime. On the other hand, the EPP methods greatly simplify the design evaluation procedure by eliminating the need for stress classification, which is the basis of the current simplified design rules. The goal of this EPP+SMT methodology is to maximize the advantages of both EPP methods and the SMT CF evaluation approach. This EPP+SMT method aims to minimize the over-conservatism in the existing $\mathrm{CF}$ evaluation procedure using the damage interaction diagram, while properly accounting for enhanced creep damage around localized defects and stress risers.

A detailed plan has been developed and revised for the development of this EPP+SMT methodology (Wang et al., 2016a, 2016b, 2017a, 2018, 2019, Messner, 2018). The development of SMT-based design curves requires experimental data, and the parameters to be considered include elastic follow-up factor, strain range, loading rate, test temperature, hold time, and primary load. In the original SMT key feature testing methods, the elastic follow-up factor was achieved by sizing the length and area ratios of the driver section to the test section. Achievement of the requisite representation of creep damage characteristics using key featured SMT, particularly at very high temperatures, involves specimen configurations that are both costly and beyond the limits of test control and stability (Wang et al., 2013, 2014, 2015, 2016a, 2017b, 2017c). Although key featured SMT testing is crucial in the verification of the SMT-based design methodology, it is not practical to be used for generating SMT-based design curves.

Recently, major progress was made in developing SMT experimental techniques by Wang et al. (2018, 2019). In particular, the newly developed single-bar SMT (SBSMT) test method and test protocol overcome many challenges associated with conducting SMT key feature experiments and enable the evaluation of the effect of elastic follow-up using a standard CF specimen without the need for specialized instrumentation and specimen design. In FY 2019, Wang et al. (2019) demonstrated the SBSMT method on Alloy 617, SS316H, and Gr.91 by testing at high temperatures and successfully showed the flexibility of generating SMT-based failure data with a wide range of elastic follow-up values from 1 to 12. It was shown that the SBSMT test method significantly simplifies the procedure for generating SMT test data and enables the development of a SMT-based design method to advance at a rapid pace.

Messner et al. (2019) demonstrated through analysis that the effect of elastic follow-up, characterized by the factor $q$, on CF life can be simplified by imposing a reduction factor of $(1 / q)$ to the standard CF data at 
the same temperature, strain range and hold time. Preliminary evaluation of the previous SMT data generated at ORNL showed promising results, although more detailed analysis and test data are needed for further verification. By taking advantage of the standard CF test database, the development of $\mathrm{EPP}+\mathrm{SMT} \mathrm{CF}$ design methodology took a major leap forward. The remaining critical factors in determining the SMT-based design curves are the effect of the primary load and the method for extrapolation on the hold time.

In this reporting period, the SBSMT experimental technique was successfully extended to pressurized tubular specimen geometry, and the results were used to evaluate the effect of primary pressure load on the SMT CF life of Alloy 617 at $950^{\circ} \mathrm{C}$. In addition, an analysis was performed to evaluate the hold time effect on SMT-based design curves for Alloy 617, and testing on the hold time effect was initiated on Alloy 617 at $950^{\circ} \mathrm{C}$.

\section{MATERIAL}

The Alloy 617 specimens were machined out of the Alloy 617 plate with heat number 314626 from ThyssenKrupp VDM USA, Inc. The plate has a nominal thickness of $38 \mathrm{~mm}$. The chemical composition of the plate is listed in Table 1.

Table 1. Chemical compositions of Alloy 617 plate with heat number 314626 (weight \%)

\begin{tabular}{c|c|c|c|c|c|c|l|l|l|l|l|c}
\hline $\mathbf{C}$ & $\mathbf{S}$ & $\mathbf{C r}$ & $\mathbf{N i}$ & $\mathbf{M n}$ & $\mathbf{S i}$ & $\mathbf{M o}$ & $\mathbf{T i}$ & $\mathbf{C u}$ & $\mathbf{F e}$ & $\mathbf{A l}$ & $\mathbf{C o}$ & $\mathbf{B}$ \\
\hline 0.05 & $<0.002$ & 22.2 & $\mathrm{R} 54.1$ & 0.1 & 0.1 & 8.6 & 0.4 & 0.04 & 1.6 & 1.1 & 11.6 & $<0.001$ \\
\hline
\end{tabular}

The specimen longitudinal direction is oriented along the rolling direction of the plate. All the specimens were tested in the as-received condition.

\section{EFFECT OF PRIMARY PRESSURE LOAD ON SMT CREEP-FATIGUE LIFE OF ALLOY 617}

In the current $\mathrm{CF}$ evaluation approach based on the damage-diagram, the effect of primary load is accounted for in the process of calculating the accumulated creep damage fraction. However, the primary load effect in the EPP+SMT methodology will need to be evaluated independently. In the original SMT concept by Jetter (1998), the effects of sustained primary stress loading were considered to be negligible because the allowable local stress and strain levels were much higher than the allowable sustained primary stress levels, per ASME code. For example, for a 100k hr design life, the allowable primary stress, $S_{m t}$, for Alloy 617 at $950^{\circ} \mathrm{C}$ is only $5 \mathrm{MPa}$, while the local, deformation controlled stresses from the stress vs. time plots in this report are an order of magnitude and more higher. However, this key assumption on the effect of primary load on the SMT CF life requires experimental verification of the actual effects. At ORNL, experiments were designed using an internal-pressure-induced primary load imposed onto tubular-shaped SMT test specimens for the evaluation. This section summarizes the previous pressurized SMT test results on Alloy 617, explains the extension of the SBSMT technique for primary load evaluation, and discusses the results and the methods to account for the primary load effects on SMT-based design curves. 


\subsection{SUMMARY OF PREVIOUS PRESSURIZED SMT TEST RESULTS}

The original pressurized SMT experiments were performed on tubular SMT specimens designed with a predetermined value of the elastic follow-up factor, $q$. The pressurized SMT specimen and the test setup are shown in Fig. 1. The test specimen has an inner diameter of $12.7 \mathrm{~mm}(0.5 \mathrm{in}$.$) and a necked test$ section with a wall thickness of $1.524 \mathrm{~mm}(0.06 \mathrm{in}$.). The surface finish of the both inner wall and outer wall are kept to be No.8. The elastic follow-up effect is produced by the stress and strain redistribution of the thicker wall tubular section, i.e., the driver section, and the thinner wall necked test section. The elastic follow-up factor is a function of the specimen geometry, i.e., the area ratio and the length ratios of the two sections, and the creep behavior of the material.

The SMT method requires testing of a specimen with accurate end displacement control for the control length. Wang et al. (2014, 2015, 2016a, 2016b) explained the details of the testing procedure. Testing was performed by cyclically applying an end-displacement to the control length while maintaining a constant internal pressure load. In this case, the total effective control length was $127 \mathrm{~mm}$ (5 in.), as shown in

Fig. 1. A second extensometer with a $10.16 \mathrm{~mm}(0.4 \mathrm{in})$ gage length was placed in the necked test section of the SMT specimen to measure the axial strain during the test. The stress-strain hysteresis loops were therefore obtained from these tests. The internal pressurization and axial loading put the test specimen under a multi-axial stress state.

All the SMT tests performed on Alloy 617 at $950^{\circ} \mathrm{C}$ and $850^{\circ} \mathrm{C}$ were pressurized internally with $99.9999 \%$ pure helium. Test results with tension hold loading are summarized in Table 2. Calculating from the allowable stress for 100,000 hr design life for Alloy 617, the internal pressure is limited to approximately $1.03 \mathrm{MPa}(150 \mathrm{psi})$ at $950^{\circ} \mathrm{C}$ and $2.76 \mathrm{MPa}(400 \mathrm{psi})$ at $850^{\circ} \mathrm{C}$ for this specimen geometry. For comparison purpose, SBSMT experiments were also performed on specimens with very small internal pressure of $0.01 \mathrm{MPa}(2 \mathrm{psi})$, which introduces negligible primary stress but keeps the specimen from oxidation on the inner wall surface.

A schematic of the stress-strain response for the pressurized SMT test is shown in Fig. 2. The elastic follow-up in this report is defined from the stress-strain hysteresis loops where axial stress was from axial load measured by the load cell and the axial strain was measured from the necked test section. In this case, the elastic follow-up factor is defined as the ratio of axial relaxation strain with elastic follow-up, $\varepsilon_{0-2}$, to axial strain without elastic follow-up, $\varepsilon_{0-1}$. The elastic follow-up factor is about 4.1 for this SMT geometry for Alloy 617 at $950^{\circ} \mathrm{C}$.

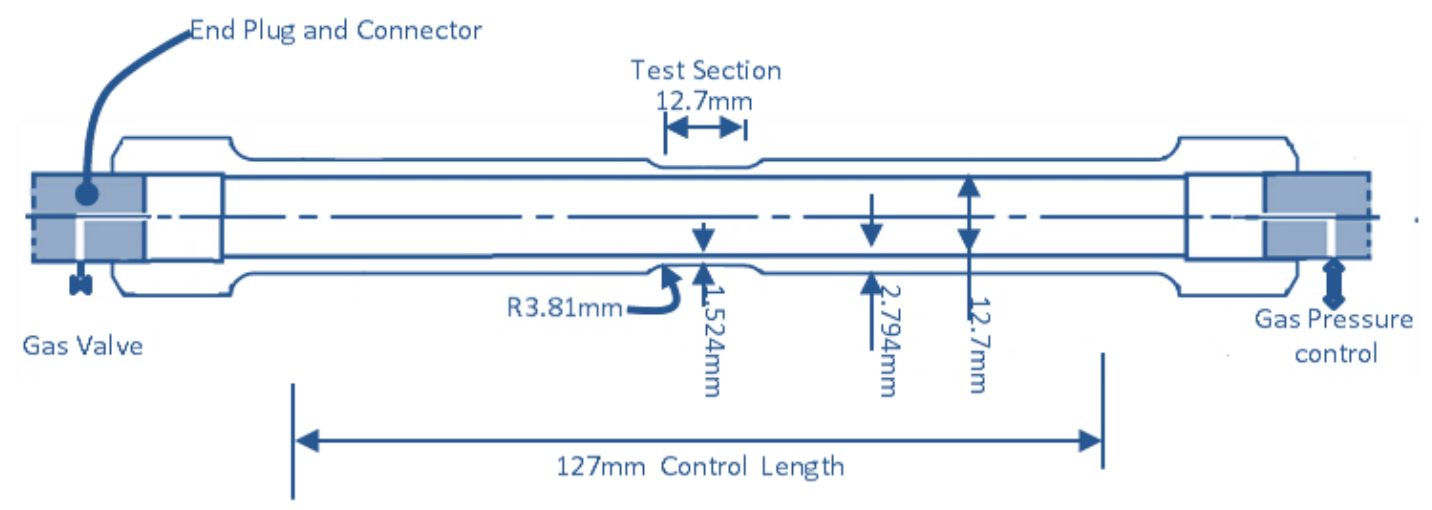

Fig. 1. Pressurization SMT specimen and experimental setup. 


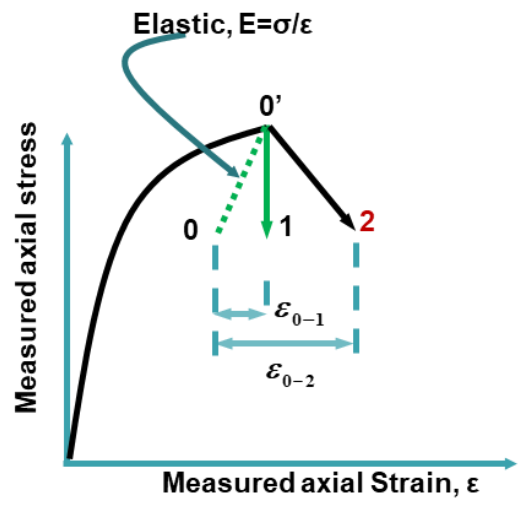

Fig. 2. Axial stress-strain curve with elastic follow-up for the pressurized SMT

At a large strain range and a high test temperature of $950^{\circ} \mathrm{C}$, the SMT CF life was found to decrease when the internal pressure was higher than $1.38 \mathrm{MPa}(200 \mathrm{psi})$, but the effect was insignificant when the internal pressure was lower than $1.38 \mathrm{MPa}$ (200psi). However, based on limited test data at an intermediate strain range of $\sim 0.25 \%$, SMT CF life decreased when the allowable internal pressure of $1.03 \mathrm{MPa}$ (150psi) was applied. However, the two tests at a lower temperature of $850^{\circ} \mathrm{C}$ and an intermediate strain range did not reveal an effect of internal pressure. Therefore, the limited experimental data showed that the effect of primary load is dependent on both test temperature and strain ranges.

The effect of primary load on the SMT design curve is an important aspect of the SMT-based design methodology. Additional SMT tests with internal pressurization at different strain ranges, temperatures, hold times and elastic flow-ups are certainly needed to understand the data scatter and fully evaluate the effect of primary load on the SMT CF life.

Table 2. Results of previous pressurized SMT testing for Alloy 617 with $600 \mathrm{~s}$ tension hold

\begin{tabular}{|c|c|c|c|c|c|c|}
\hline $\begin{array}{c}\text { Specimen } \\
\text { ID }\end{array}$ & $\begin{array}{c}\text { Amplitude, } \\
\delta \text { value }\end{array}$ & \begin{tabular}{|c|}
$\begin{array}{c}\text { Initial strain } \\
\text { range }\end{array}$ \\
\end{tabular} & \begin{tabular}{|c|} 
Test temperature \\
$\left({ }^{\circ} \mathrm{C}\right)$
\end{tabular} & Internal pressure & \begin{tabular}{|c|}
$\begin{array}{c}\text { Lifetime } \\
(\mathrm{hr})\end{array}$ \\
\end{tabular} & $\begin{array}{c}\begin{array}{c}\text { Cycles to } \\
\text { failure }\end{array} \\
\end{array}$ \\
\hline INC617-P01 & \multirow{5}{*}{$0.114 \mathrm{~mm}$ (4.5 mils) } & $0.8 \%$ & 950 & $0.01 \mathrm{MPa}(2 \mathrm{psi})$ & \begin{tabular}{|l|}
37.4 \\
\end{tabular} & 220 \\
\hline INC617-P02 & & $0.8 \%$ & 959 & $1.38 \mathrm{MPa}(200 \mathrm{psi})$ & 37.4 & 220 \\
\hline INC617-P04 & & $0.8 \%$ & 957 & 3.45MPa (500 psi) & 34 & 200 \\
\hline INC617-P03 & & $0.75 \%$ & 958 & \multirow{3}{*}{$5.17 \mathrm{MPa}(750 \mathrm{psi})$} & 25.5 & 150 \\
\hline INC617-P06 & & $0.8 \%$ & 950 & & 23.8 & 140 \\
\hline INC617-P09 & $0.076 \mathrm{~mm}$ (3 mils) & --- & 953 & & 54.4 & 320 \\
\hline INC617-P10 & $0.025 \mathrm{~mm}(1 \mathrm{mils})$ & $0.12 \%$ & 950 & 1.03MPa (150psi) & $>6408$ & $>37,693$ \\
\hline INC617-P11* & \multirow{3}{*}{$\begin{array}{c}0.0635 \mathrm{~mm} \\
(2.5 \mathrm{mils})\end{array}$} & $0.4 \%$ & 950 & 1.05MPa (150 psi) & 18.7 & 110 \\
\hline INC617-P12 & & $0.25 \%$ & 950 & $0.01 \mathrm{MPa}(2 \mathrm{psi})$ & 231.2 & 1360 \\
\hline INC617-P13 & & $0.25 \%$ & 950 & $1.05 \mathrm{MPa}(150 \mathrm{psi})$ & 139.4 & 820 \\
\hline INC617-P14 & \multirow{2}{*}{$\begin{array}{l}0.0762 \mathrm{~mm} \\
(3 \mathrm{mils})\end{array}$} & $0.21 \%$ & 850 & $2.76 \mathrm{MPa}(400 \mathrm{psi})$ & 584.2 & 3440 \\
\hline INC617-P15 & & $0.25 \%$ & 850 & $0.01 \mathrm{MPa}(2 \mathrm{psi})$ & 584.8 & 3460 \\
\hline
\end{tabular}

Note: * INC617-P11 is for information only. The initial large strain range indicates a specimen with possible defects. 


\subsection{EXTENSION OF SBSMT TECHNIQUE FOR EVALUATION OF THE EFFECT OF PRIMARY PRESSURE LOAD}

In the original SMT key feature testing methods, the elastic follow-up factor was achieved by sizing the length and area ratios of the driver section to the test section. In some cases, testing with large elastic follow-up that requires long specimens becomes impractical due to specimen buckling. In addition, the precise end-displacement control becomes critical due to the increased extensometer span. The SBSMT technique effectively resolves these critical challenges and enables the use of standard CF specimens to generate CF failure data with elastic follow-up. The SBSMT method captures the essential features of a test article with elastic follow-up, i.e., the retarded stress relaxation and the enhanced CF damage. The test setup and procedure for the SBSMT are much simpler and similar to the standard CF test described in ASTM E2714 (2020). The major difference is the addition of the strain component for generating the equivalent strain signal from the measured load and then combining it with the strain from the test specimen to form the control strain signal (Wang et al., 2019). These features can be implemented relatively easily in most modern test controllers. For example, McMurtrey et al. (2020) at Idaho National Laboratory successfully implemented the SBSMT test technique on their testing system, illustrating the practicability of the SBSMT testing method.

To take advantage of this newly developed SBSMT method, a tubular specimen configuration was designed to evaluate the effect of primary pressure load on SMT CF life. The tubular geometry allows internal pressure-induced primary load, and the SBSMT provides a much more compact specimen design. A drawing of the specimen is shown in Fig. 3.

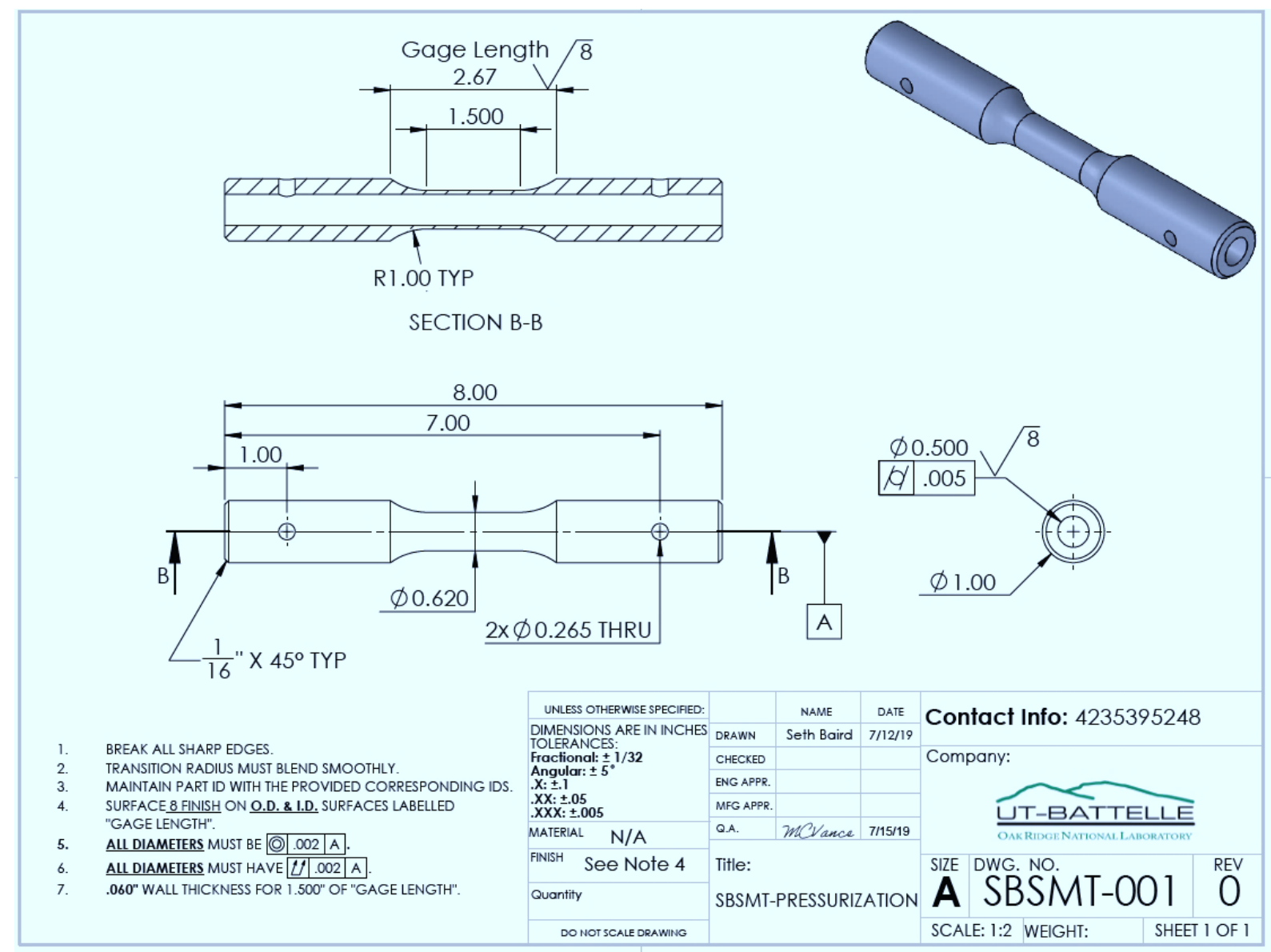

Fig. 3. Specimen geometry of pressurized SBSMT. Units are in inches. 
The wall thickness, internal diameter, and surface finish requirement of the gage section of the pressurized SBSMT specimen are the same as the necked test section of the original tubular SMT specimen shown in Fig. 1. A picture of the test specimens is shown in Fig. 4. By using the pressurized SBSMT method, testing of the primary load effect on SMT CF life is much easier and simpler. The complex issues of ratcheting and barreling in the original pressurized SMT are expected to be resolved or minimized by the SBSMT method.

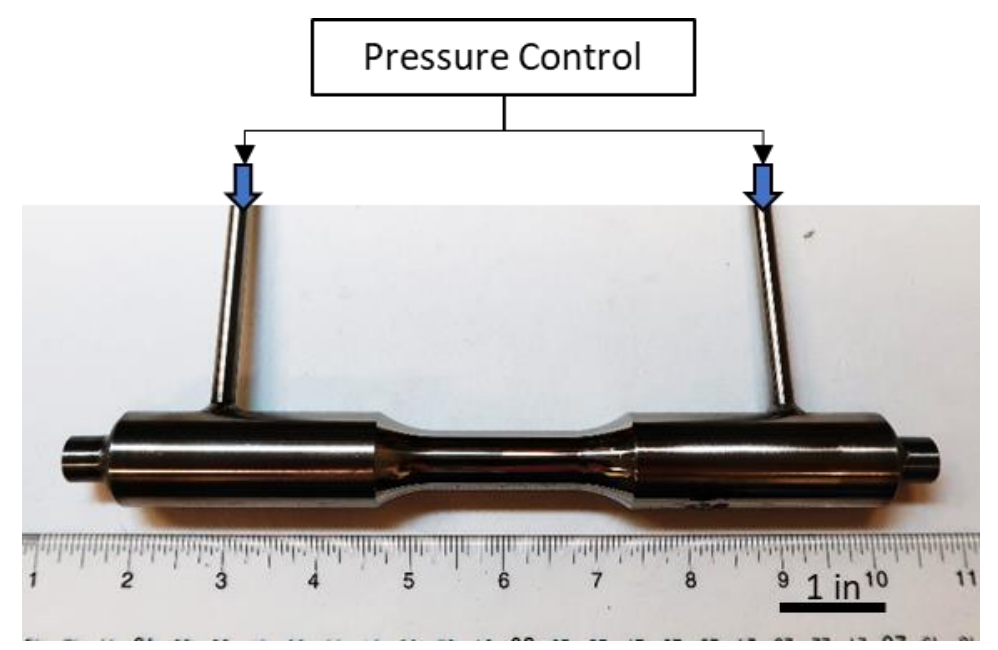

Fig. 4. Picture of the pressurized SBSMT Alloy 617 specimen.

SBSMT tests with internal pressurization for Alloy 617 were designed to study the effect of primary load on the $\mathrm{CF}$ behavior at $950^{\circ} \mathrm{C}$. Five cylindrical tubular specimens of Alloy 617 were prepared. Two different internal pressures, i.e. negligible $0.01 \mathrm{MPa}(2 \mathrm{psi})$ and the maximum allowable pressure $1.03 \mathrm{MPa}$ (150psi), were applied on the Alloy 617 specimens. The tests were performed under the strain-control condition with a $600 \mathrm{~s}$ tensile holding time at selected target strain ranges of $0.18 \%, 0.25 \%$, and $0.50 \%$, and selected elastic follow-up factors of 2.0,3.5, and 6.0. The strain loading ratio, $R$, was -1 . Table 3 summarizes the target testing parameters for the specimens studied in this report.

Table 3. Testing parameters of pressurized SBSMT on Alloy 617 at $950^{\circ} \mathrm{C}$.

\begin{tabular}{|c|c|c|c|c|c|c|}
\hline $\begin{array}{l}\text { Specimen } \\
\text { ID }\end{array}$ & $\begin{array}{c}\text { Temperature, } \\
{ }^{\circ} \mathrm{C}\end{array}$ & Internal pressure & $\begin{array}{c}\text { Elastic } \\
\text { follow-up } \\
\text { factor }\end{array}$ & $\begin{array}{l}\text { Holding } \\
\text { segment }\end{array}$ & Hold time, $s$ & $\begin{array}{l}\text { Target strain } \\
\text { range }\end{array}$ \\
\hline SBAP5 & \multirow{5}{*}{950} & 1.03MPa (150psi) & 3.5 & \multirow{5}{*}{ Tension } & \multirow{5}{*}{600} & $0.50 \%$ \\
\hline SBAP6 & & $0.01 \mathrm{MPa}(2 \mathrm{psi})$ & 3.5 & & & $0.50 \%$ \\
\hline SBAP9 & & $0.01 \mathrm{MPa}(2 \mathrm{psi})$ & 2.0 & & & $0.18 \%$ \\
\hline SBAP7 & & 1.03MPa (150psi) & 2.0 & & & $0.25 \%$ \\
\hline SBAP4 & & $0.01 \mathrm{MPa}(2 \mathrm{psi})$ & 6.0 & & & $0.25 \%$ \\
\hline
\end{tabular}

\subsubsection{Effect of Internal Pressure on SBSMT with an Elastic Follow-up of 3.5 at $950^{\circ} \mathrm{C}$}

In this section, the test results for SBAP5 (with internal pressure of 1.03MPa (150psi)) and SBAP6 (with internal pressure of $0.01 \mathrm{MPa}(2 \mathrm{psi})$ ) using the pressurized SBSMT method at $950^{\circ} \mathrm{C}$ are discussed. The hysteresis loops of SBAP5 and SBAP6 for cycle 1,2, and 3 and their mid-life cycles are compared in Fig. 5a. The hysteresis loops of SBAP5 with 1.03MPa (150psi) applied internal pressure show little difference 
compared with SBAP6 with 0.01MPa (2psi) applied pressure. The elastic follow-up factors calculated for these selected cycles are almost identical for both tests. Fig. $4 \mathrm{~b}$ presents the elastic follow-up factors measured in SBAP5 and SBAP6 as a function of applied cycles. It qualitatively illustrates that upon reaching the stable cycles for both tests, the elastic follow-up factors remain almost constant until the failure initiation, and the results show that SBAP6 had a $3.53 \pm 0.04$ elastic follow-up factor, and SBAP5 exhibited a slightly lower average elastic follow-up factor of $3.40 \pm 0.03$.

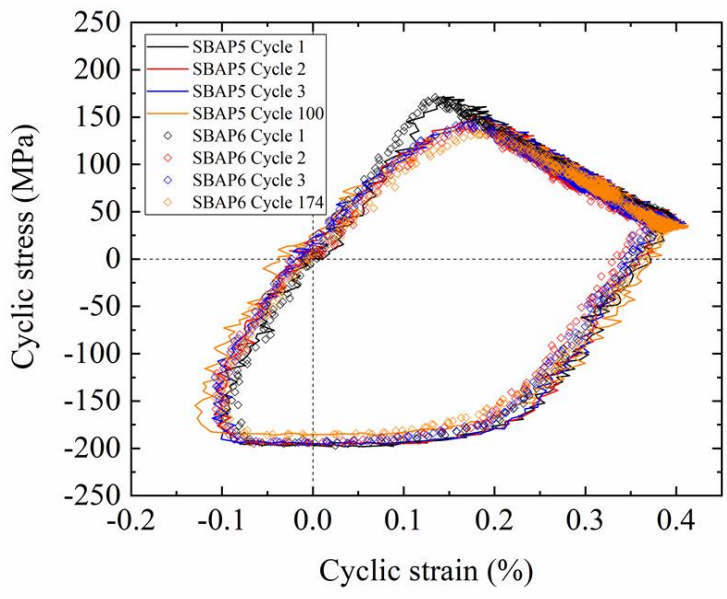

(a)

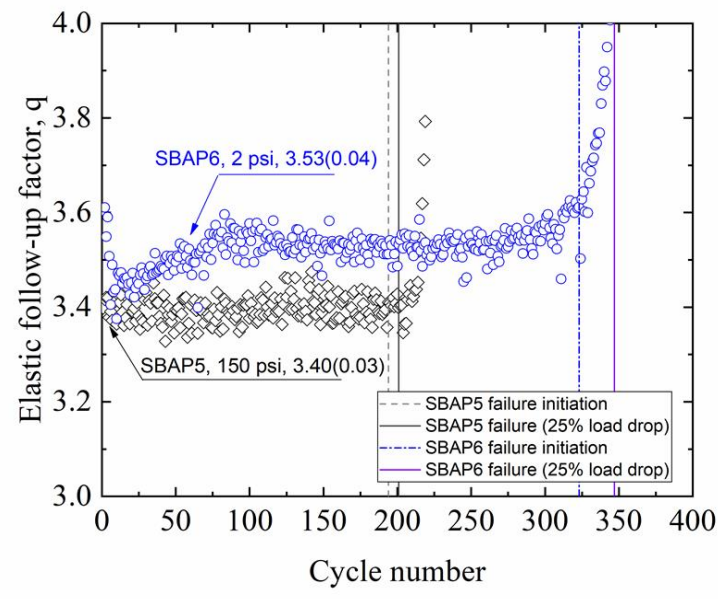

(b)

Fig. 5. (a) Representative hysteresis loops and (b) elastic follow-up factor as a function of applied cycles for SBAP5 and SBAP6.

The maximum/minimum stresses, strain ranges and maximum/minimum strains for SBAP5 and SBAP6 are compared in

Fig. 6. Both tests showed an initial strain range of about $0.5 \%$ followed by a slight increase to reach a value of about $0.53 \%$ during the first 50 cycles; then the strain ranges stabilized with an increase in applied cycles, as shown in

Fig. 6b. The average strain ranges in SBAP5 with 1.03MPa (150psi) pressure load were slightly higher than those of SBAP6. SBAP5 showed slightly lower minimum strains (

Fig. 6c). The CF life was determined to be 194 cycles for SBAP5 (1.03MPa (150psi)) and 323 cycles for SBAP6 (0.01MPa (2psi)), based on the analysis of maximum stress development. Note that the cycles to failure initiation were used as a measure of CF life.

To quantitively analyze the stress relaxation behavior during the tension holding segment in pressurized SBSMT tests, the parameters including the stresses at the beginning and the end of the holding segment and the loading strain ranges were extracted from the test data. These parameters are identified on a schematic hysteresis loop shown in Fig. 7. In this case, the loading strain range, $\Delta \varepsilon_{\text {loading }}$, and the total strain range, $\Delta \varepsilon$, are defined as

$$
\Delta \varepsilon_{\text {loading }}=\varepsilon_{1}-\varepsilon_{3}
$$




$$
\Delta \varepsilon=\varepsilon_{2}-\varepsilon_{3}
$$

The stress at the beginning of the holding segment is $\sigma_{1}$ and the stress at the end of the holding segment is $\sigma_{2}$. The extra creep strain accumulated during the relaxation segment due to the elastic follow-up effect is $\left(\varepsilon_{2}-\varepsilon_{1}\right)$.

The stress relaxation history of representative cycles, the evolution of maximum stresses at the beginning and the end of the hold and the loading strain ranges are compared for SBAP5 and SBAP6 in Fig. 8. The stress relaxation was significant in both tests during the tension hold with approximately $60 \%$ load drop occurred in the initial $50 \mathrm{~s}$ of the hold. The stress relaxation behavior did not show a significant difference between these two tests. The stresses at the beginning of the holding segment for the $1.03 \mathrm{MPa}(150 \mathrm{psi})$ case were slightly higher as compared with those for the $0.01 \mathrm{MPa}(2 \mathrm{psi})$ test, consistent with the slightly higher loading strain ranges for SBAP5. After the initial 25 cycles, the stresses at end of the holding segment of both tests remained approximately constant with additional applied cycles until failure initiation.

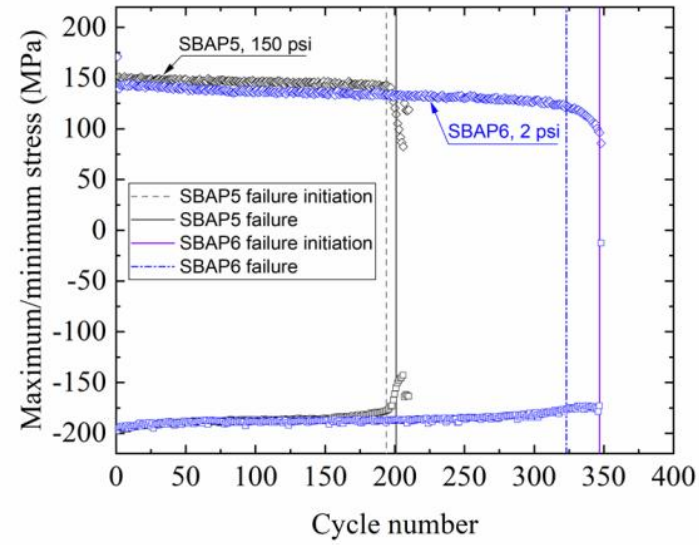

(a)

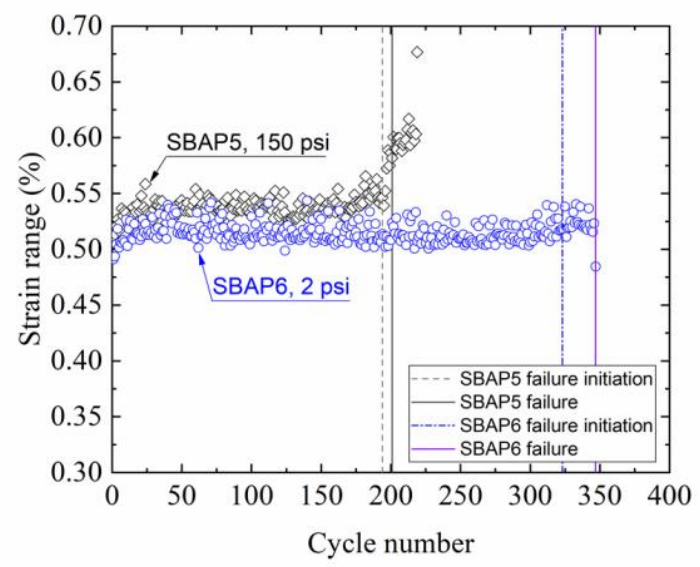

(b)

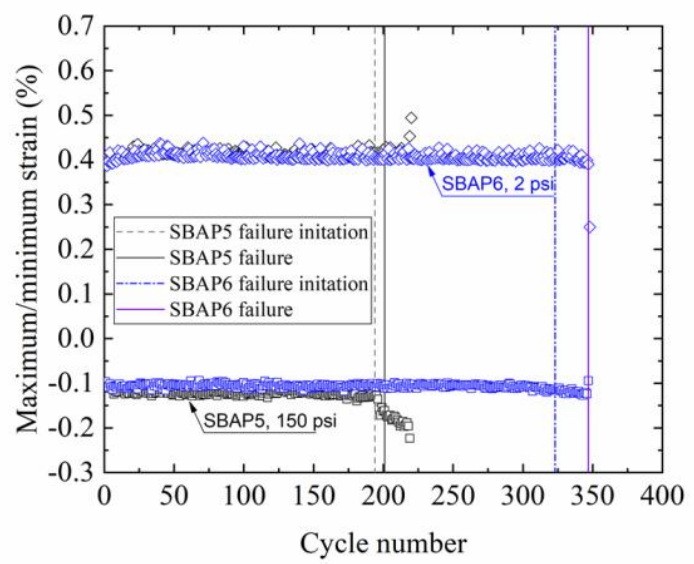

(c)

Fig. 6. Comparison of (a) maximum and minimum stresses, (b) strain ranges, and (c) maximum and minimum strains for SBAP5 and SBAP6 as a function of applied cycles. 


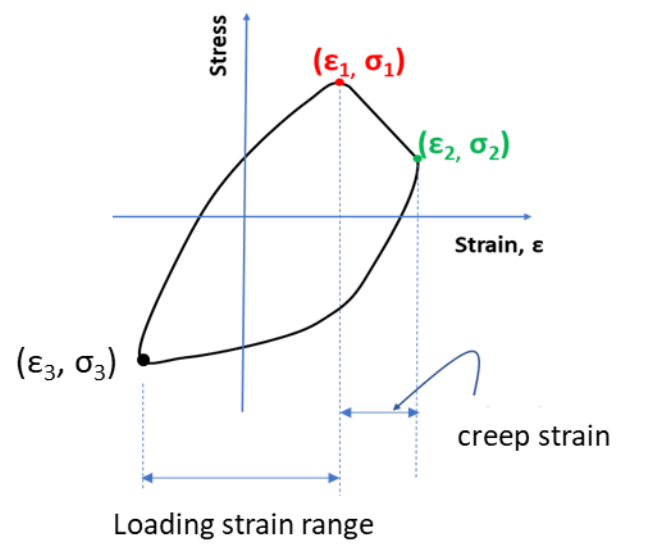

Fig. 7. Characteristics of the hysteresis loop of the SBSMT test.

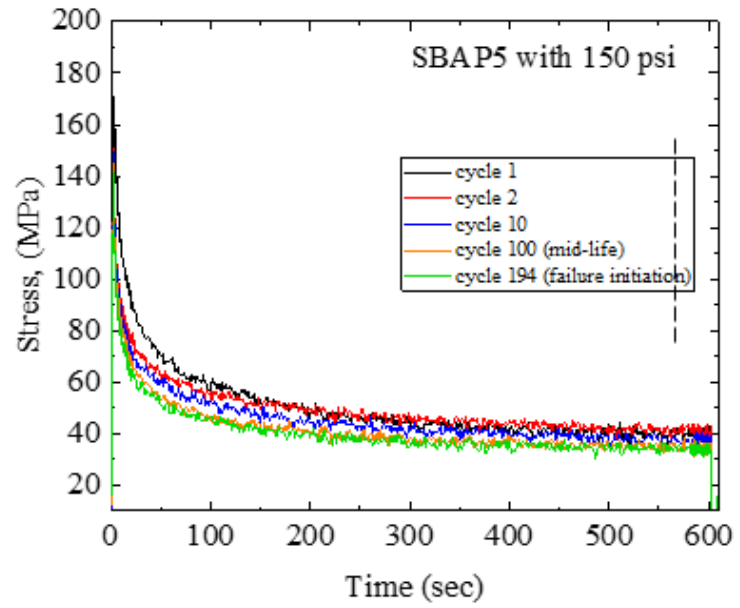

(a)

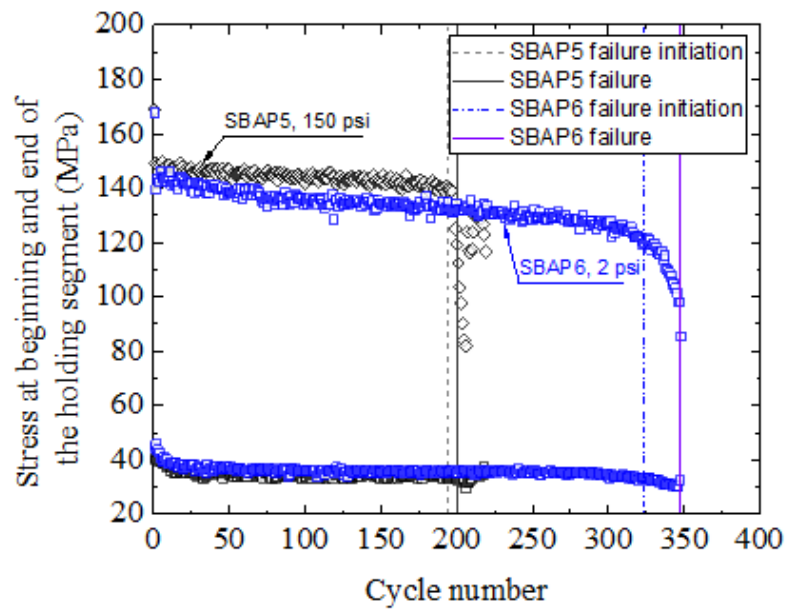

(c)

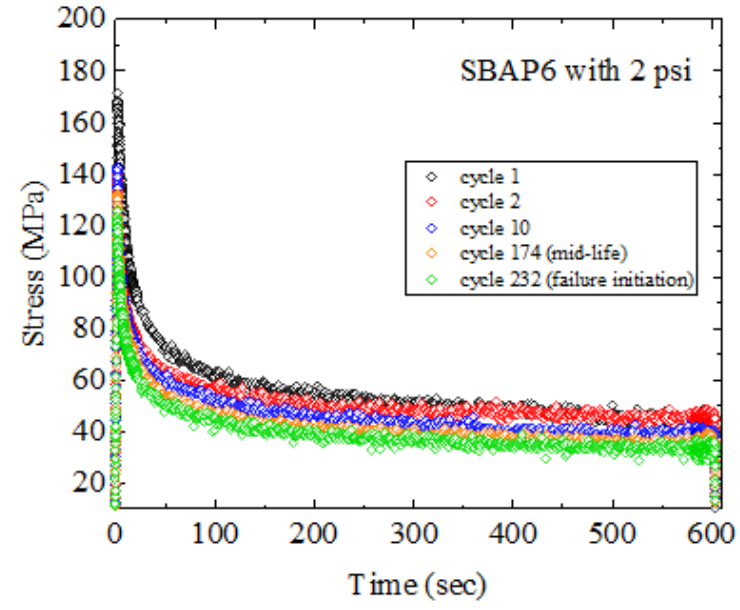

(b)

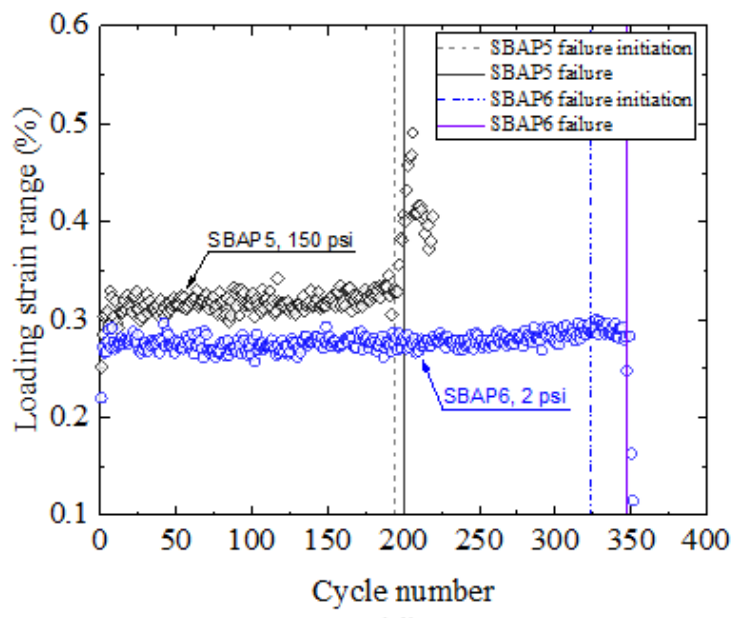

(d)

Fig. 8. Comparison of stress histories of representative cycles for (a) SBAP5 and (b) SBAP6 and comparison of (c) the stress relaxation behavior during holding segment and (d) the loading strain ranges as a function of applied cycles 
The results for SBAP5 and SBAP6 are summarized in Table 4. The increase in internal pressure resulted in a reduction of creep-fatigue life of Alloy 617 at $950^{\circ} \mathrm{C}$ at this strain range of $0.53 \%$, which is consistent with our previous data on Alloy 617 from the original SMT test at $950^{\circ} \mathrm{C}$ with a higher elastic follow-up factor of 4.1 (Wang et al. 2019). A picture of the failed specimens is shown in Fig. 9. Both specimens failed outside the control extensometer gage. The failure location and failure mode were the same for the two specimens.

Table 4. Pressurized SBSMT results of SBAP5 and SBAP6

\begin{tabular}{c|c|c|c|c|c|c}
\hline Specimen ID & $\begin{array}{c}\text { Internal } \\
\text { pressure }\end{array}$ & $\begin{array}{c}\text { Elastic } \\
\text { follow-up } \\
\text { factor, } \boldsymbol{q}\end{array}$ & $\begin{array}{c}\text { Initial stable } \\
\text { strain range } \\
\Delta \boldsymbol{\varepsilon}, \boldsymbol{\%}\end{array}$ & $\Delta \boldsymbol{\varepsilon}_{\text {loading }} \boldsymbol{\%}$ & Hold time, $\mathbf{s}$ & $\begin{array}{c}\text { Cycles to } \\
\text { failure }\end{array}$ \\
\hline SBAP5 & $\begin{array}{c}1.03 \mathrm{MPa} \\
(150 \mathrm{psi})\end{array}$ & $3.40 \pm 0.03$ & 0.53 & 0.32 & 600 & 201 \\
\hline SBAP6 & $\begin{array}{c}0.01 \mathrm{MPa} \\
(2 \mathrm{psi})\end{array}$ & $3.53 \pm 0.04$ & 0.53 & 0.27 & 600 & 347 \\
\hline
\end{tabular}

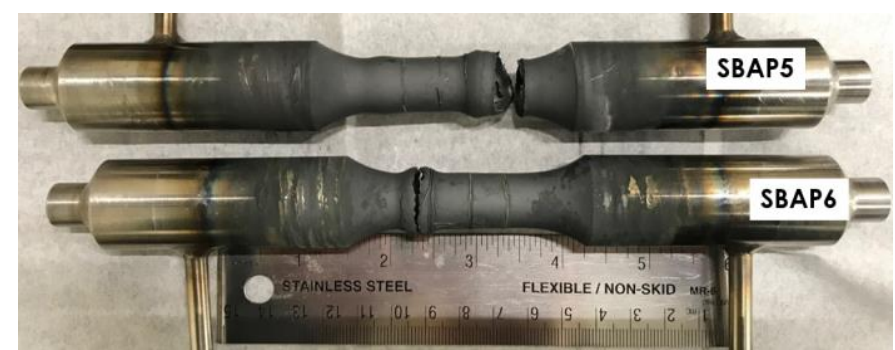

Fig. 9. Picture of the SBAP5 and SBAP6 after testing

\subsubsection{Effect of Internal Pressure on SBSMT with an Elastic Follow up of 2 at $950^{\circ} \mathrm{C}$}

Pressurized SBSMT testing was also performed with a lower elastic follow-up factor of 2 on Alloy 617 at $950^{\circ} \mathrm{C}$, with $1.03 \mathrm{MPa}(150 \mathrm{psi})$ for SBAP9 and $0.01 \mathrm{MPa}(2 \mathrm{psi})$ for SBAP7. The tests were performed at low strain ranges with the same applied control displacement. The testing parameters and the results on SBAP9 and SBAP7 are listed in Table 5. The SMT CF life was 996 cycles for SBAP9 with an internal pressure of $1.03 \mathrm{MPa}(150 \mathrm{psi})$ and with a slightly higher measured strain range of $0.28 \%$, whereas SBAP7 tested with an internal pressure of $0.01 \mathrm{MPa}(2 \mathrm{psi})$ showed a much longer CF life of 3224 cycles to failure with a strain range of $0.25 \%$.

Table 5. Pressurized SBSMT results of SBAP9 and SBAP7

\begin{tabular}{c|c|c|c|c|c|c}
\hline Specimen ID & $\begin{array}{c}\text { Internal } \\
\text { pressure }\end{array}$ & $\begin{array}{c}\text { Elastic } \\
\text { follow-up } \\
\text { factor, } \boldsymbol{q}\end{array}$ & $\begin{array}{c}\text { Initial stable } \\
\text { strain range } \\
\Delta \boldsymbol{\varepsilon}, \boldsymbol{\%}\end{array}$ & $\begin{array}{c}\Delta \boldsymbol{\varepsilon}_{\text {loading, }}, \\
\boldsymbol{\%}\end{array}$ & $\begin{array}{c}\text { Hold time, } \\
\mathbf{s}\end{array}$ & $\begin{array}{c}\text { Cycles to } \\
\text { failure }\end{array}$ \\
\hline SBAP9 & $\begin{array}{c}1.03 \mathrm{MPa} \\
(150 \mathrm{psi})\end{array}$ & $1.96 \pm 0.03$ & 0.28 & 0.21 & 600 & 996 \\
\hline SBAP7 & $\begin{array}{c}0.01 \mathrm{MPa} \\
(2 \mathrm{psi})\end{array}$ & $2.02 \pm 0.04$ & 0.25 & 0.19 & 600 & 3224 \\
\hline
\end{tabular}


Comparisons of the representative hysteresis loops and the measured elastic follow-up factors for SBAP9 and SBAP7 are presented in Fig. 10. As shown, SBAP9 and SBAP7 exhibit almost identical hysteresis loops for the initial cycles, and the elastic follow-up factors are similar for the two tests. Moreover, as the applied cycles were increased, the elastic follow-up factors stayed almost constant and comparable for the two tests. The average elastic follow-up was $1.96 \pm 0.03$ for SBAP9 and $2.02 \pm 0.04$ for SBAP7 until the onset of failure.

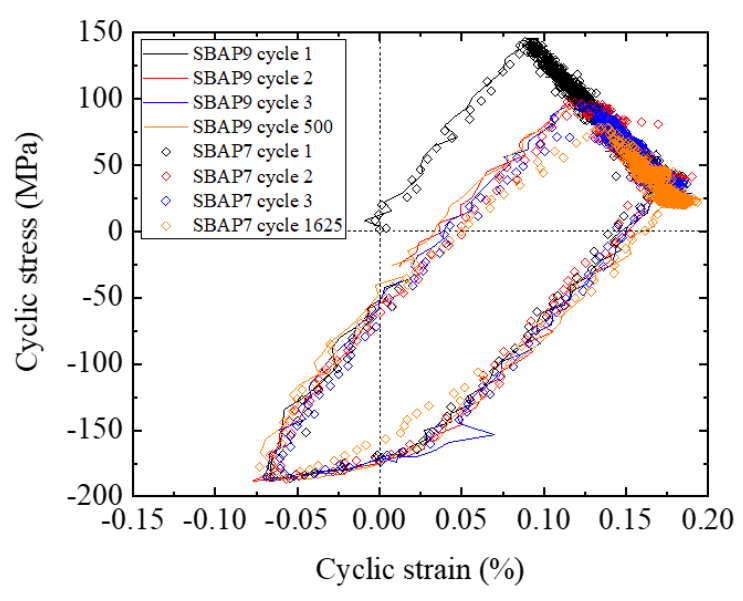

(a)

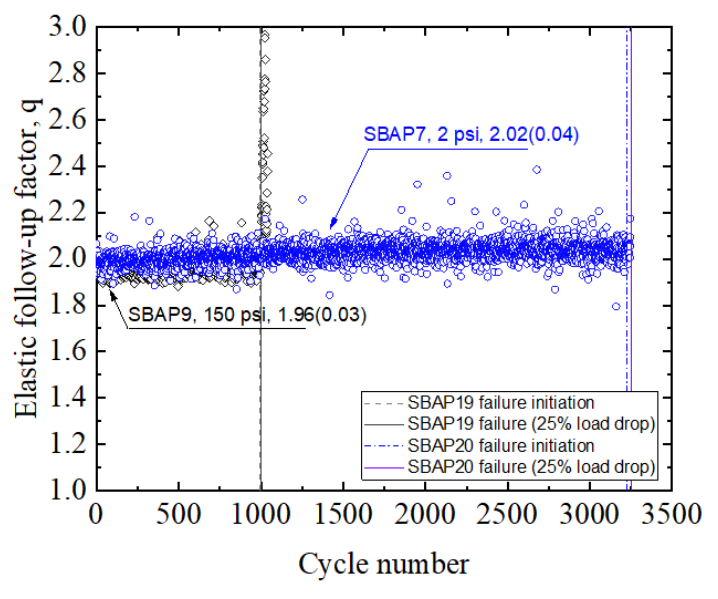

(b)

Fig. 10. (a) Representative hysteresis loops and (b) elastic follow-up factors as a function of applied cycles for SBAP9 and SBAP7

Fig. 11 presents the maximum/minimum stress, strain ranges and maximum/minimum strain of SBAP9 and SBAP7 as a function of applied cycles. The maximum/minimum stresses, strain ranges and maximum/minimum strains are comparable from the beginning of the cycles to the failure initiation for SBAP9. A slight decrease in the maximum and minimum stresses as a function of applied cycles were observed in SBAP7. An increase in the strain ranges was consistent with the increased measured maximum and minimum strains as the applied cycles were increased for SBAP7. 


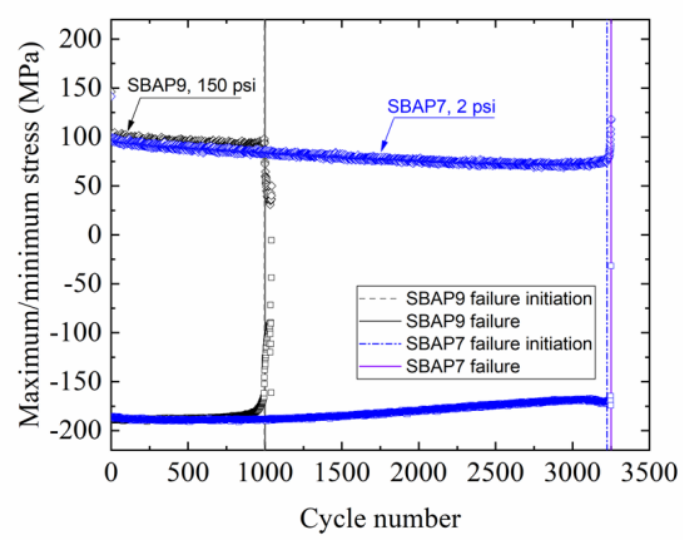

(a)

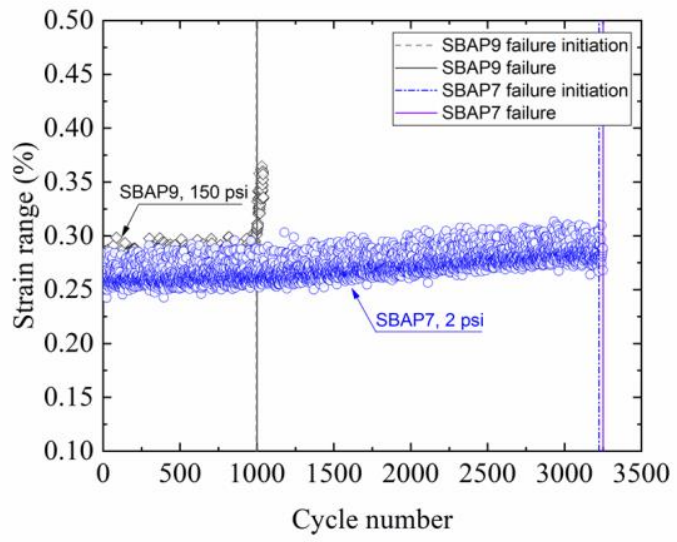

(b)

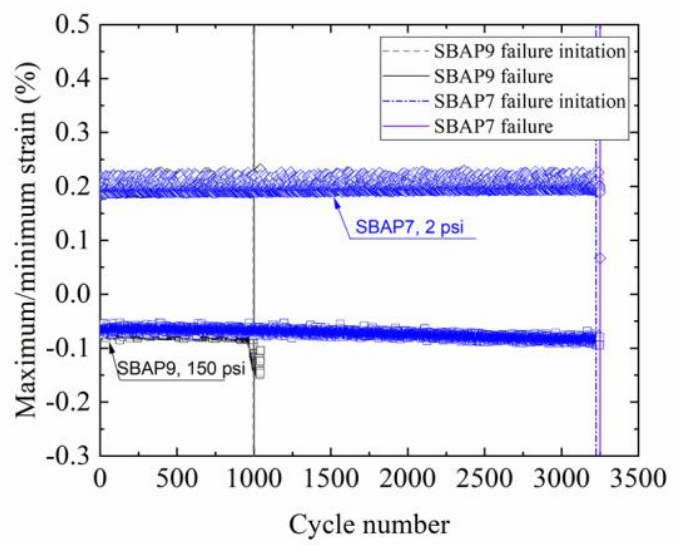

(c)

Fig. 11. Comparison of (a) maximum and minimum stresses, (b) strain ranges and (c) maximum and minimum strains as a function of applied cycles for SBAP9 and SBAP7.

The stress relaxation history of representative cycles, the stresses at the beginning and the end of the hold along with the loading strain ranges as a function of the applied cycles are compared for SBAP9 and SBAP7 in Fig. 12. Both tests showed significant stress relaxation during the 600 s hold, but SBAP9 with the higher internal pressure showed higher stresses at the beginning of the holding segment and larger stress relaxation at the end of the holding segment than the SBAP7, as shown in Fig. 12c. In addition, the loading strain ranges of the SBAP7 were slightly lower than SBAP9, although the applied control displacements were the same. Such differences seem to be consistently observed for both sets of tests with different elastic follow-up factors and are correlated with the amount of internal pressure load. 


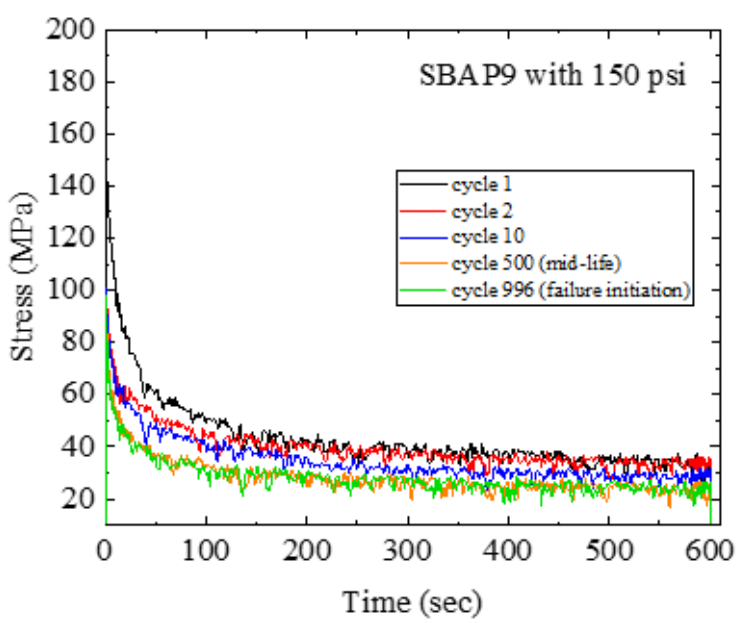

(a)

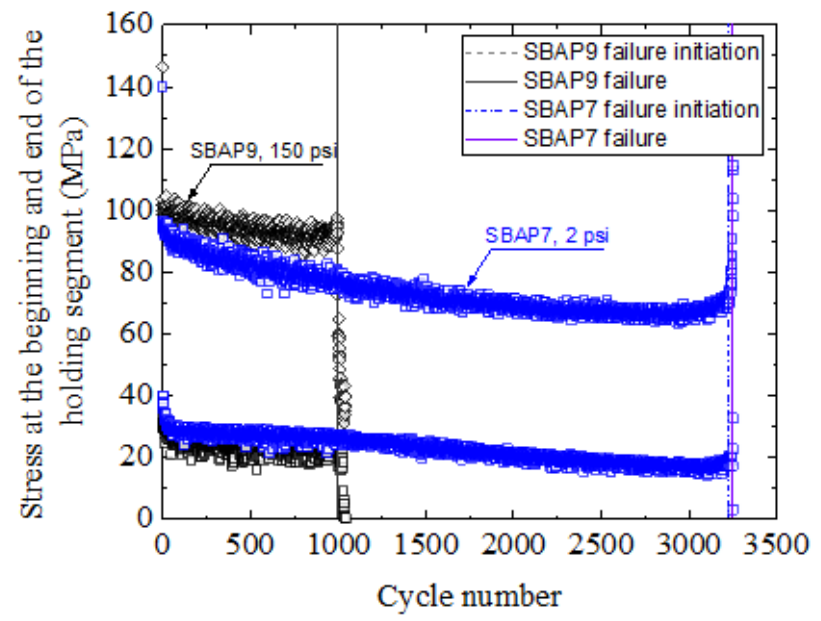

(c)

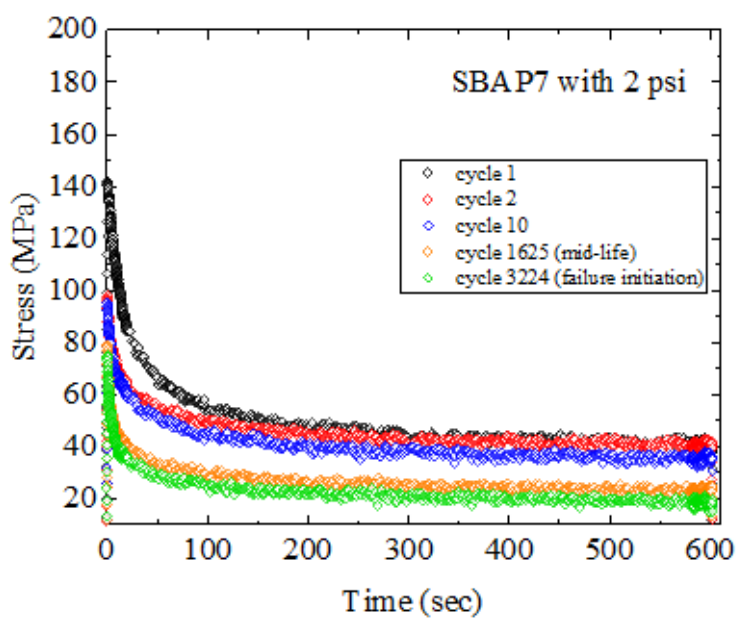

(b)

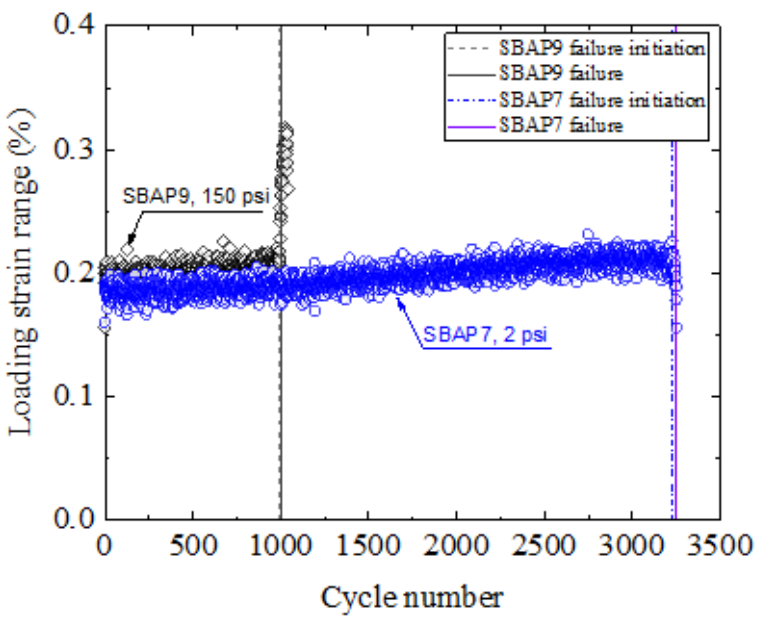

(d)

Fig. 12. Comparison of the stress histories of representative cycles for (a) SBAP9 and (b) SBAP7 and comparison of (c) the stress relaxation behavior during holding segment and (d) the loading strain ranges as a function of applied cycles

A picture of the failed specimens is shown in Fig. 13. SBAP9 with 150 psi internal pressure failure location showed significant bulging but SBAP7 did not. 

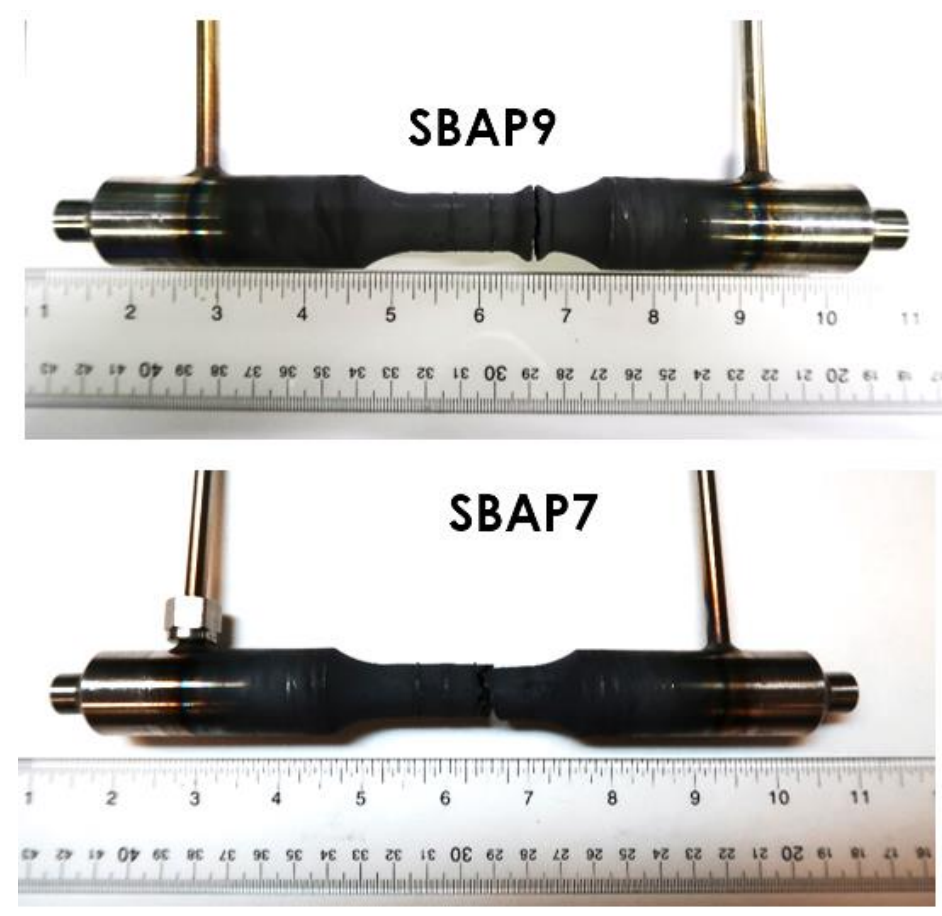

Fig. 13. Picture of the SBAP9 and SBAP7 after testing.

\subsubsection{SBSMT with an Elastic Follow-up of 6 at $950^{\circ} \mathrm{C}$}

One additional SBSMT test was carried out on SBAP4 for Alloy 617 at $950^{\circ} \mathrm{C}$ with a large elastic followup of 6 in the low strain range region using the tubular shaped specimen. A small internal pressure of $0.01 \mathrm{MPa}(2 \mathrm{psi})$ was applied to keep the specimen inner wall from oxidizing. The representative hysteresis loops and measured elastic follow-up factors are presented in Fig. 14. An average elastic follow-up factor of $6.10 \pm 0.12$ was achieved. Except for the first cycle, the hysteresis loops became wider with the increase in applied cycles.

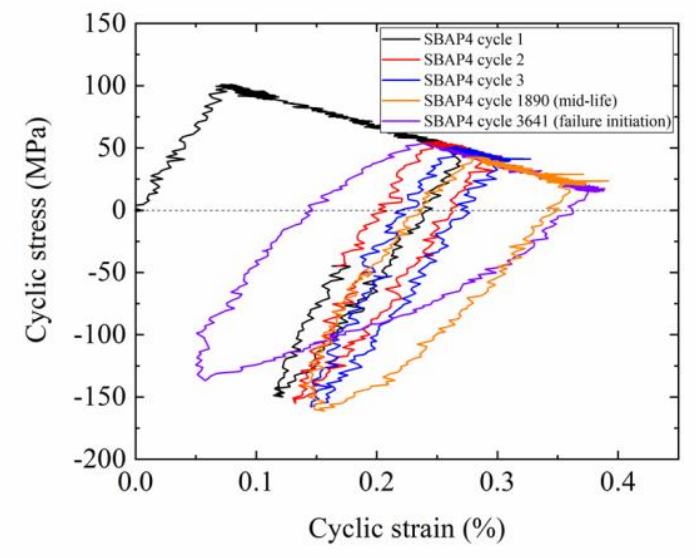

(a)

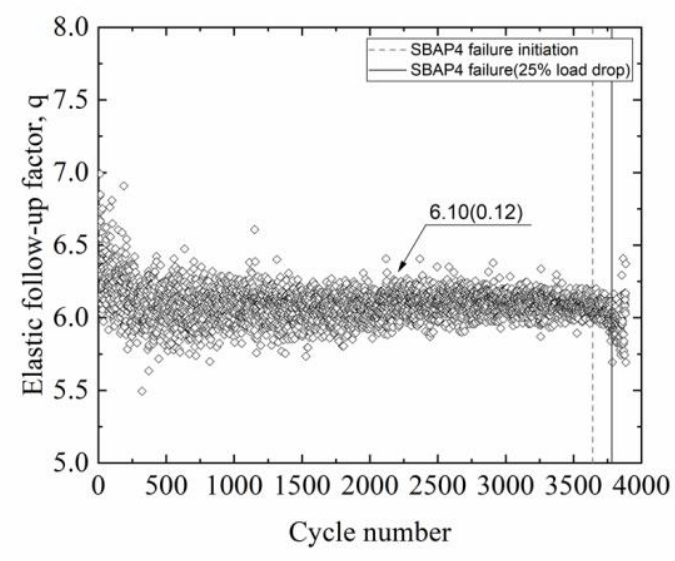

(b)

Fig. 14. (a) Representative hysteresis loops and (b) the elastic follow-up factors as a function of applied cycles for SBAP4. 
Fig. 15 shows the maximum/minimum stresses, strain range, and maximum/minimum strain as a function of applied cycles. The cycles to failure initiation were 3641 . The strain ranges increased gradually from the initial $0.18 \%$ to $0.35 \%$ upon failure initiation. The increase in the strain range was due to the increased maximum compressive strain value, as shown in Fig. 15c.

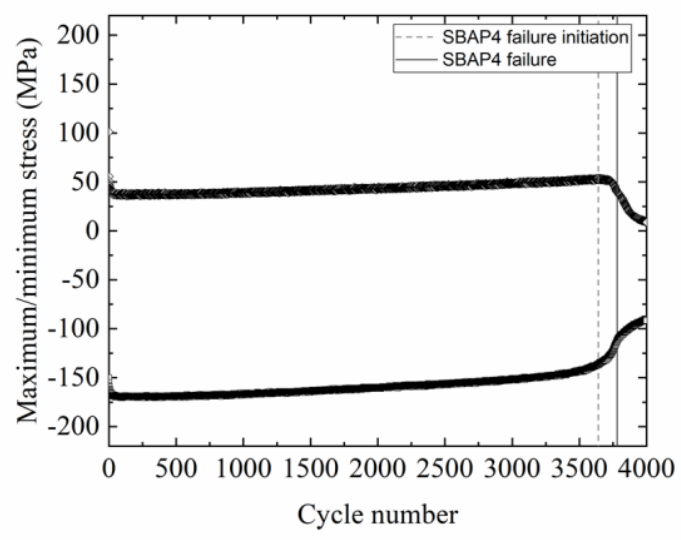

(a)

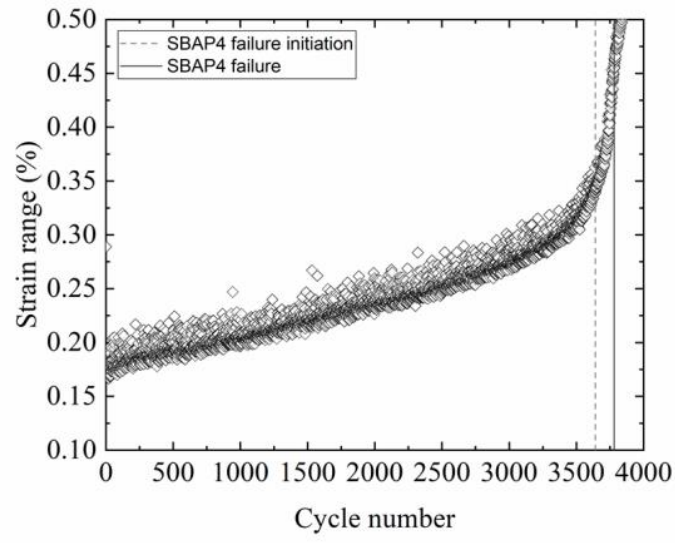

(b)

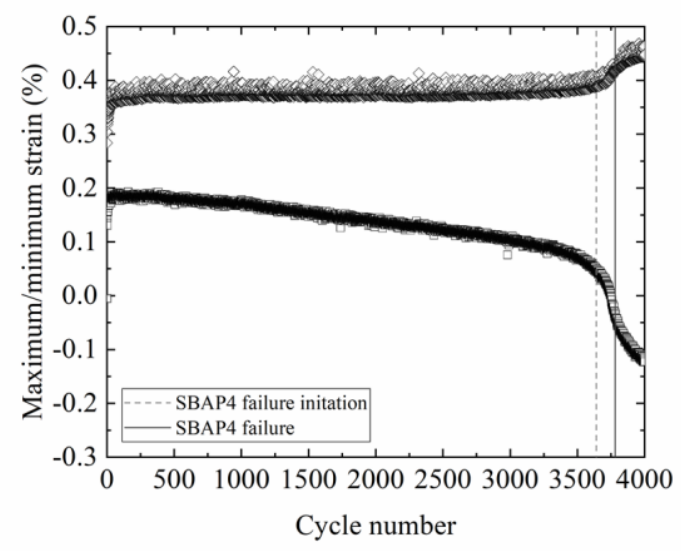

(c)

Fig. 15. (a) Maximum and minimum stresses, (b) strain ranges, and (c) maximum and minimum strains as a function of applied cycles for SBAP4.

The stress relaxation curves for cycle numbers 1, 2, 10, 1890 (mid-life cycle), and 3641 (failure initiation) are presented in Fig. 16a. The stresses at the beginning and end of the hold and loading strain ranges as a function of applied cycle are shown in Fig. 16b and Fig. 16c. Except for the first cycle, the stresses did not show much relaxation due to the large elastic follow-up for cycles prior to mid-life (Also see Fig. 14a). However, starting from the mid-life cycles until failure initiation, a higher amount of relaxation was observed as the applied cycles increased. The increase in the loading strain range as a function of the applied cycles was not significant, therefore, the increase in the total strain range with applied cycles shown in Fig. 15c was mainly due to the increased creep strain. This was different from that observed in previous specimens. A closer look at the failed specimen depicted in Fig. 17 showed the failure location of this specimen to be at the middle of the gage section, i.e., inside the control extensometer probes. The 
difference in the failure locations is believed to be the cause of the different contributions of the loading strain range and the creep strain to the total strain range. Although the exact effect on the failure cycles due to failure location inside or outside the control extensometer gage is not clear, the differences in these tests demonstrate that one should pay attention to the details of testing with the SBSMT method. This aspect will be explored in future research.

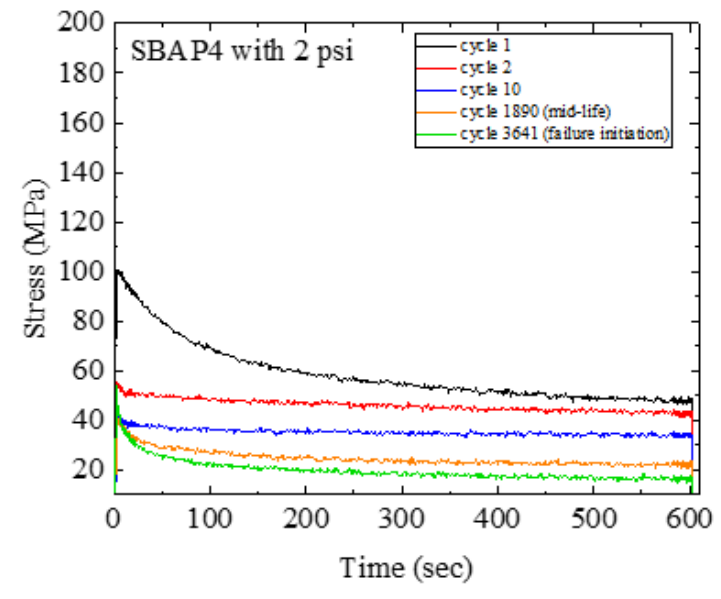

(a)

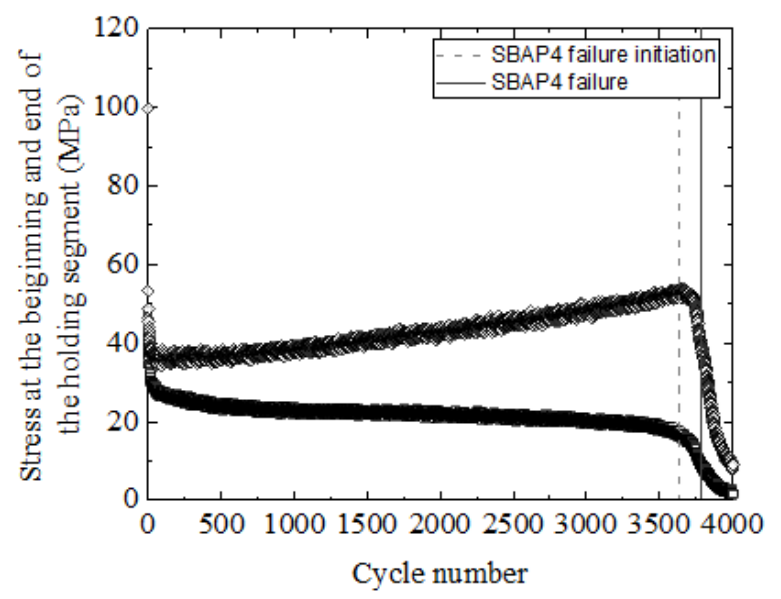

(b)

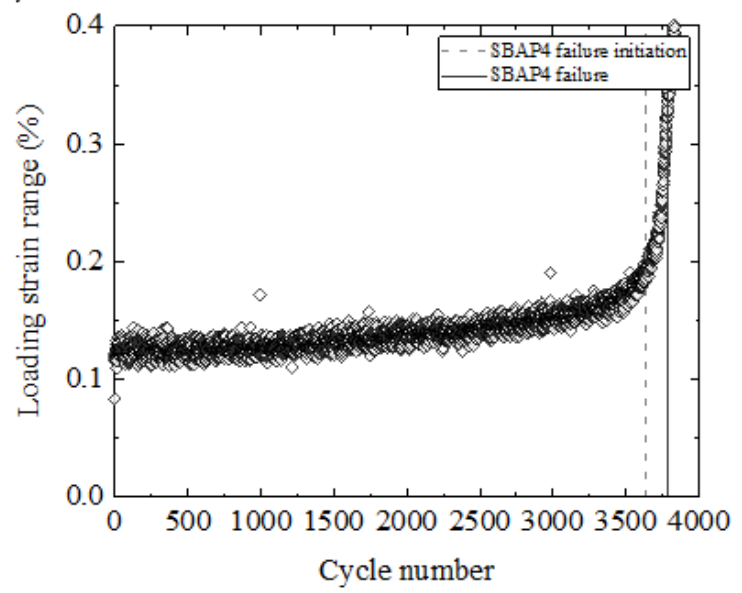

(c)

Fig. 16. (a) Stress histories of the representative hysteresis loops, (b) the stresses during holding, and (c) loading strain range as a function of applied cycles of SBAP4.

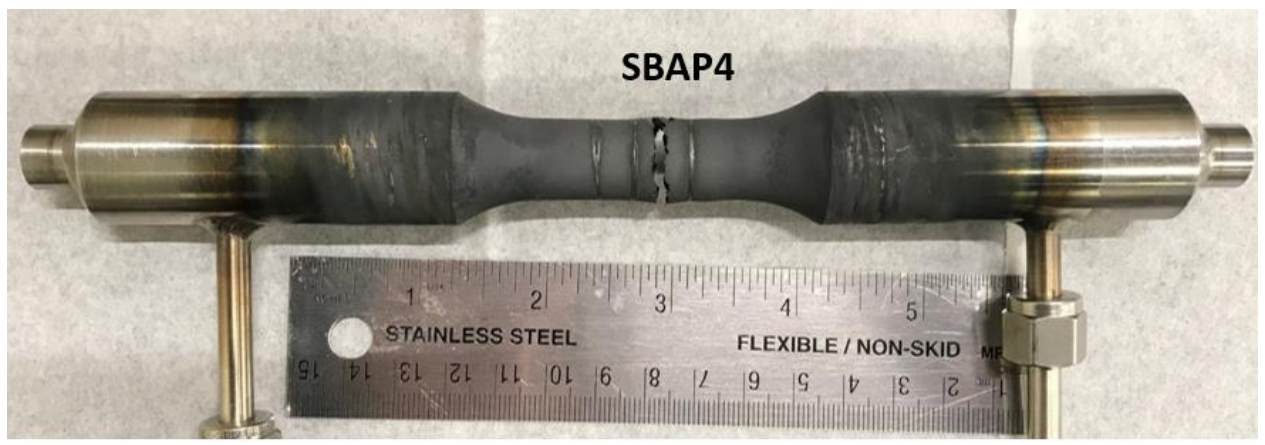

Fig. 17. Picture of SBAP4 after testing 


\subsection{SUMMARY OF THE PRESSURIZED SBSMT RESULTS ON ALLOY 617}

The results of the pressurized SBSMT on Alloy 617 tested at $950^{\circ} \mathrm{C}$ in FY 2020 are summarized in Table 6. All five test had a tension hold time of $600 \mathrm{~s}$. The results consistently showed that the $1.03 \mathrm{MPa}$ (150psi) primary pressure load reduced SMT CF life cycles. The reduction in SMT CF is more significant at lower strain ranges, consistent with previous research by Wang et al. (2019).

Table 6. Summary of the pressurized SBSMT on Alloy 617 with tension hold of $600 \mathrm{~s}$ at $950^{\circ} \mathrm{C}$.

\begin{tabular}{c|c|c|c|c|c}
\hline $\begin{array}{c}\text { Specimen } \\
\text { ID }\end{array}$ & Internal pressure & $\begin{array}{c}\text { Elastic } \\
\text { follow-up } \\
\text { factor }\end{array}$ & $\begin{array}{c}\text { Initial stable } \\
\text { strain range, } \\
\text { \% }\end{array}$ & $\begin{array}{c}\Delta \boldsymbol{\varepsilon}_{\text {loading }}, \\
\boldsymbol{\%}\end{array}$ & $\begin{array}{c}\text { Cycles to } \\
\text { failure }\end{array}$ \\
\hline SBAP5 & $1.03 \mathrm{MPa}(150 \mathrm{psi})$ & $3.40 \pm 0.03$ & 0.53 & 0.32 & 201 \\
\hline SBAP6 & $0.01 \mathrm{MPa}(2 \mathrm{psi})$ & $3.53 \pm 0.04$ & 0.53 & 0.27 & 347 \\
\hline SBAP9 & $0.01 \mathrm{MPa}(2 \mathrm{psi})$ & $1.96 \pm 0.03$ & 0.28 & 0.21 & 996 \\
\hline SBAP7 & $1.03 \mathrm{MPa}(150 \mathrm{psi})$ & $2.02 \pm 0.04$ & 0.25 & 0.19 & 3224 \\
\hline SBAP4 & $0.01 \mathrm{MPa}(2 \mathrm{psi})$ & $6.10 \pm 0.12$ & 0.18 & 0.12 & 3641 \\
\hline
\end{tabular}

\subsection{DISCUSSIONS ON THE EFFECT OF PRIMARY LOAD ON SMT CF LIFE}

The pressurized SMT test data on Alloy 617 showed the primary pressure load influences the SMT CF life. The reduction in the CF lives depends on strain range, test temperature and elastic follow-up. To fully assess the primary load effect based on experimental data would require a significant amount of testing effort, which is not practical.

To evaluate the primary load effect on the SMT-based design curve, Barua et al. (2020) at Argonne National Laboratory (ANL) performed an analysis on the original SMT pressurization test specimen. The results were very promising because the EPP analysis accurately captured the barreling and ratcheting behavior in the original SMT test, and more importantly, the EPP strain range was found to increase when the internal pressure load was increased. The increased strain range corresponds to a shorter CF life on the design curve. This EPP strain range study indicates that the EPP analysis in the EPP+SMT design procedure will naturally capture the primary load effect. Although additional selected pressurized SMT test conditions are required to further verify the EPP strain range analysis, this is a significant step forward to completion of the EPP+SMT design procedure.

\section{EFFECT OF HOLD TIME ON SMT CREEP-FATIGUE LIFE}

To generate SMT-based design curves, several parameters will need to be considered in the test program. Methodologies for extrapolating hold time effects will be required. Such extrapolation will be greatly simplified if it can be demonstrated that degradation of cyclic life with hold time saturates and that there is essentially no further degradation or that the degradation in CF life is insignificant as the hold time increases to a certain value. A design margin must be applied to the test data to account for factors such as data scatter. Messner et al. (2018) proposed a modified Coffin model to represent the hold time and elastic follow-up effects for strain-controlled CF tests, and it is expressed as

$$
N=N_{\text {fatigue }}\left(\frac{1}{q} \frac{\left(\frac{1}{1+t_{h}}\right)^{p}+D}{1+D}\right)
$$


where $N$ is the CF life, $N_{\text {fatigue }}$ is the pure fatigue life (no holding), $q$ is the elastic follow-up factor, $t_{h}$ is the hold time in hr, and $p$ and $D$ are fitting parameters from hold time test data.

Calibration of the fitting parameters was conducted using the standard fatigue and CF test data from Idaho National Laboratory (INL) on Alloy 617 with the heat number 314626, where in this case, the elastic follow-up factor equals to 1 for standard CF. $N_{\text {fatigue }}$ was generated using best fit curve for the pure fatigue test data. The two fitting parameters are listed in Table 7.

Table 7. Parameters for the modified Coffin model for Alloy 617 at $950^{\circ} \mathrm{C}$

\begin{tabular}{c|c}
\hline Parameter & value \\
\hline$p$ & 29.5 \\
\hline$D$ & 0.55 \\
\hline
\end{tabular}

The pure fatigue (PF) and CF best-fit curves based on this modified Coffin model are presented in Fig. 18 together with INL's experimental data measured at $950^{\circ} \mathrm{C}$. The elastic follow-up effect on CF life cycles is simply represented by shifting the best fit curve by a factor of $1 / q$ based on Eq. (3), and the results are shown in Fig. 18b and c with $q=2$ and $q=3.5$, respectively. In addition, the predicted reduction of CF life cycles for shorter hold times is summarized in Fig. 18d. Unfortunately, experimental data at the strain range lower than $0.30 \%$ are quite limited, and no hold time data are available. In this modified Coffin model, it is assumed that the reduction of CF life is independent of the strain range, although this assumption is not accurate in practice.

In order to obtain a qualitative assessment on the reduction of CF life due to the hold time effect, testing at low strain ranges and high cycles regions is needed. The PF test was designed to generate the baseline information necessary for the comparison of Alloy 617 material with the average best fit fatigue curve. The test was performed at a nominal strain rate of $1 \mathrm{E}-3 / \mathrm{s}$ with a strain ratio of $R=-1$ and an elastic follow-up factor of 1.0 . The target strain range was $0.17 \%$, however, due to the difficulty in strain control at such a small strain range at a high test temperature, the average strain range for this pure fatigue test was found to be $0.163 \%$.

The maximum and minimum stresses as a function of the applied cycles are plotted in Fig. 19. The small kink at 3.5E5 cycles was due to an unexpected power outage and subsequent restart of the test. The cycles to failure were 511,454. This fatigue data point is compared with the best-fit curve in Fig. 20 together with the experimental data. This test data showed about twice the life as compared to that predicted by the extrapolated best-fit curve from the INL data. 


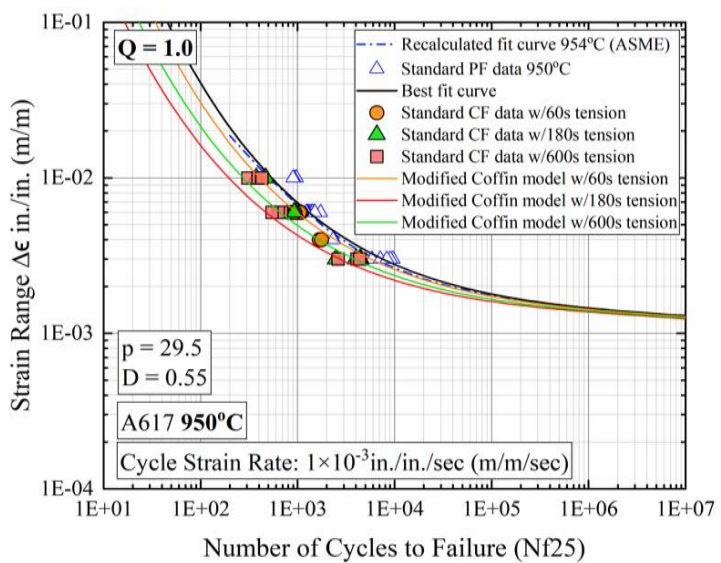

(a)

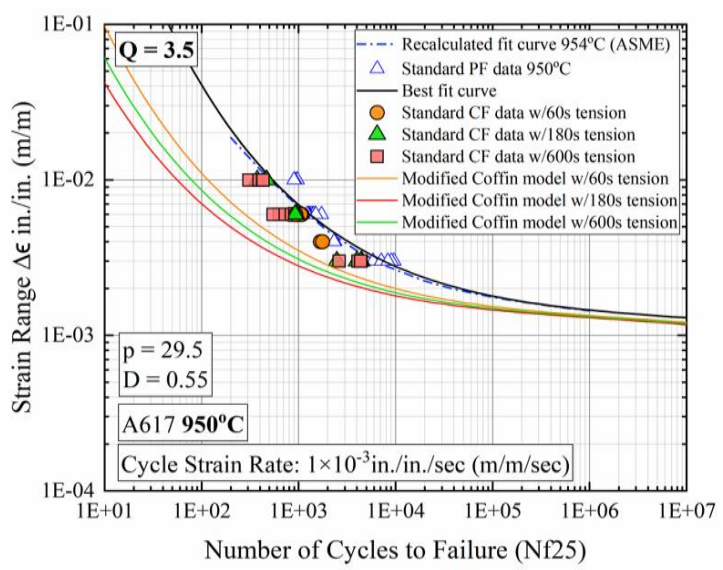

(c)

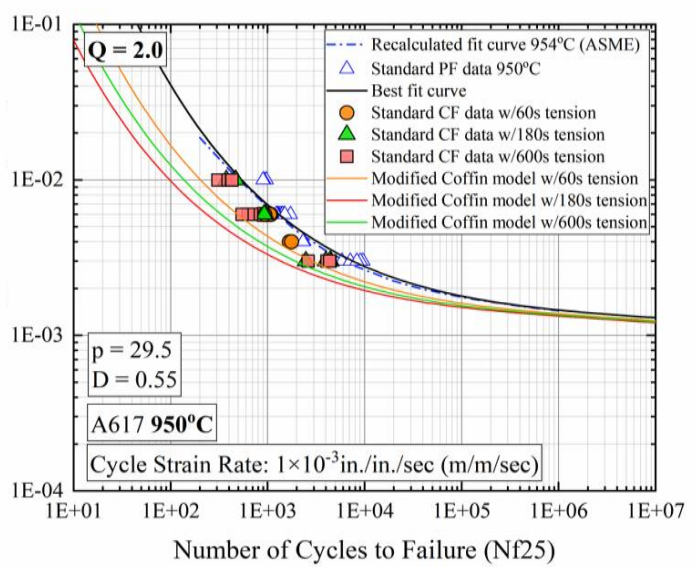

(b)

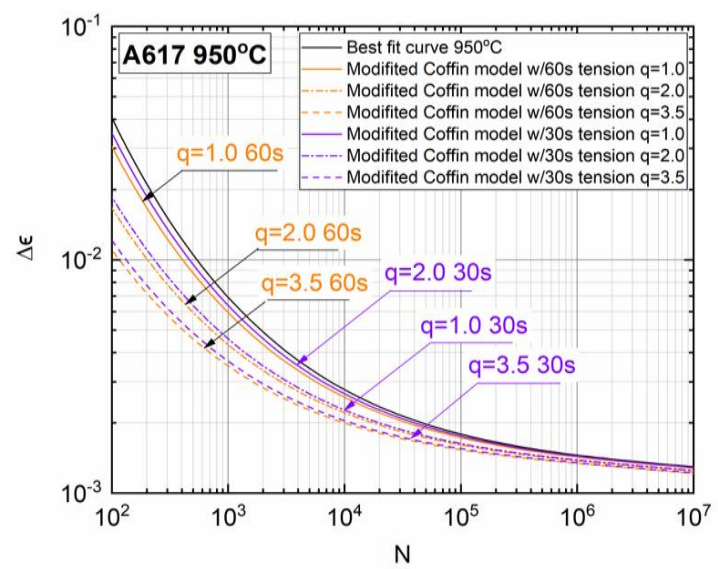

(d)

Fig. 18. Standard fatigue and CF data and modified Coffin model for Alloy 617 at $950^{\circ} \mathrm{C}$ with (a) $q=1.0$, (b) $q=2.0$, (c) $q=3.5$, and (d) predicted short hold time effect

The estimated CF cycles with various hold times at this low strain range of $0.163 \%$ based on the modified Coffin model extrapolated to low strain ranges are tabulated in Table 8. To generate CF failure data in a reasonable time, a hold time of $20 \mathrm{~s}$ is selected for further evaluation in this study. Additional SBSMT tests of the same hold time will be performed using selected elastic follow-up factors to assess the elastic follow-up effect.

The standard CF test with a peak tension hold time of $20 \mathrm{~s}$ is on-going. Testing will continue and the cycles to failure will be used to study the influence of hold time in the reduction of the SMT cycle life. 


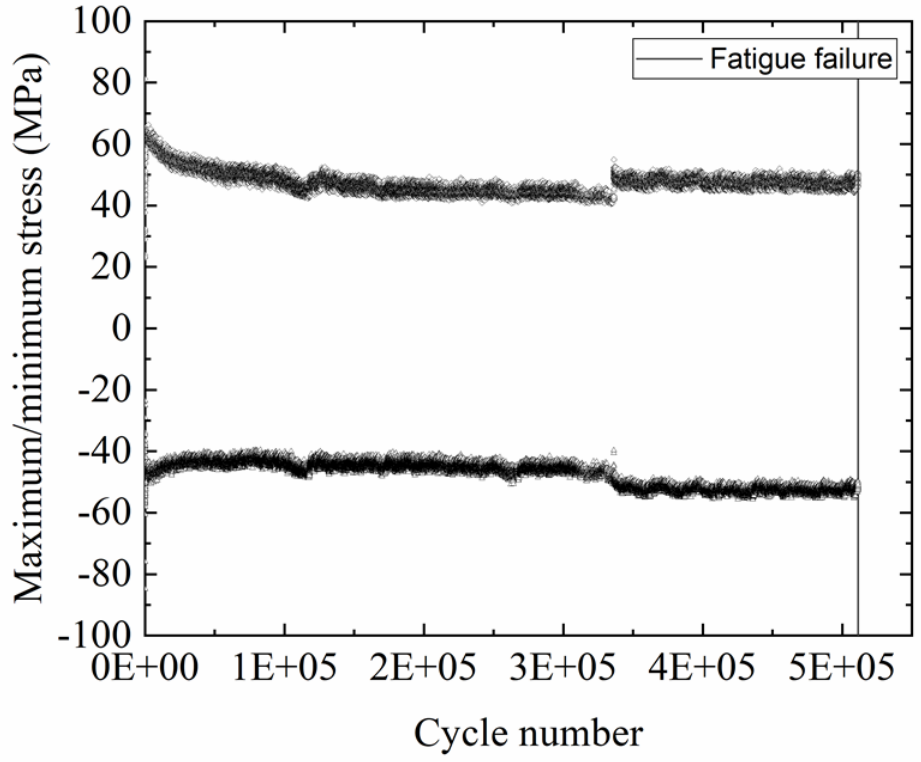

Fig. 19. Maximum and minimum stresses of strain-controlled pure fatigue test on Alloy 617 with $0.163 \%$ strain range at $950^{\circ} \mathrm{C}$.

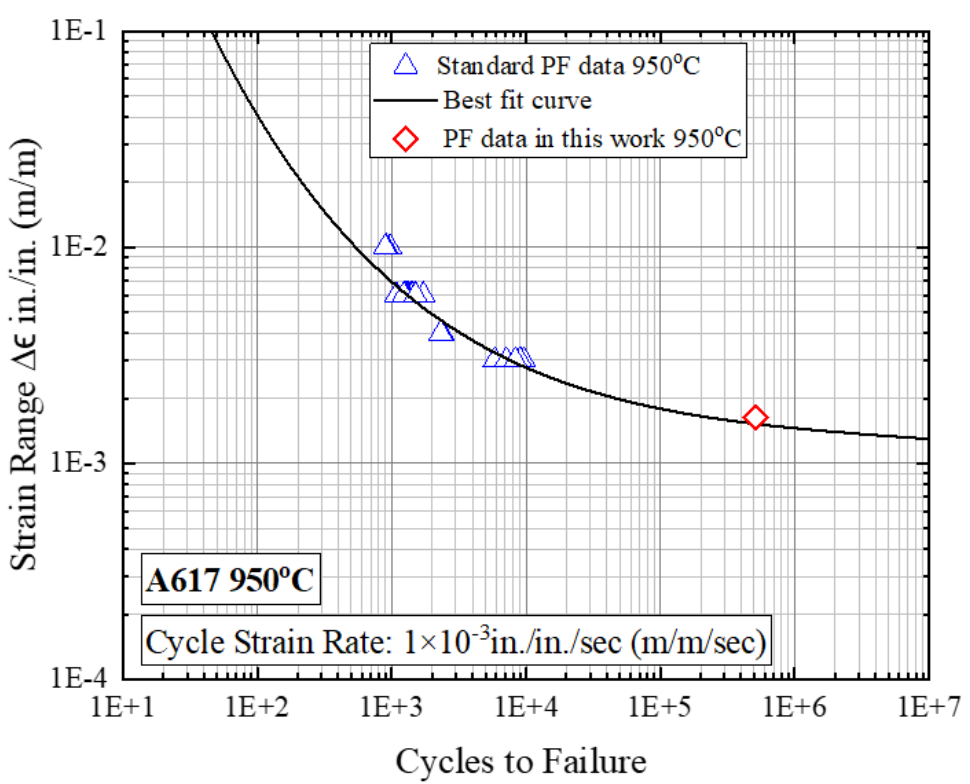

Fig. 20. Comparison of the strain-controlled pure fatigue (PF) test with the corresponding fatigue data and the best-fit curve of Alloy 617 at $950^{\circ} \mathrm{C}$. 
Table 8. Estimation of CF life and test duration using modified Coffin model for Alloy 617 at $0.163 \%$ strain range and at $950^{\circ} \mathrm{C}$.

\begin{tabular}{c|c|c|c|c|c|c}
\hline $\begin{array}{c}\text { Temperature, } \\
{ }^{\mathbf{0}} \mathbf{C}\end{array}$ & $\begin{array}{c}\text { Strain rate, } \\
\text { /s }\end{array}$ & $\begin{array}{c}\text { Elastic } \\
\text { follow-up, } \\
\boldsymbol{q}\end{array}$ & $\begin{array}{c}\text { Strain range, } \\
\mathbf{\%}\end{array}$ & $\begin{array}{c}\text { Hold time, } \\
\mathbf{s}\end{array}$ & $\begin{array}{c}\text { Estimated } \\
\text { cycles }\end{array}$ & $\begin{array}{c}\text { Estimated } \\
\text { duration, } \\
\text { month }\end{array}$ \\
\hline 950 & $1 \mathrm{E}-3$ & 1.0 & 0.163 & 0 & $5.11 \mathrm{E}+05$ & 0.6 \\
& & & & 20 & $4.62 \mathrm{E}+05$ & 4.1 \\
& & & & 30 & $4.40 \mathrm{E}+05$ & 5.6 \\
\hline 950 & $1 \mathrm{E}-3$ & 2.0 & 0.163 & 0 & $2.6 \mathrm{E}+05$ & 0.3 \\
& & & & 20 & $1.05 \mathrm{E}+05$ & 2.1 \\
& & & & 30 & $1.00 \mathrm{E}+05$ & 2.8 \\
\hline 950 & $1 \mathrm{E}-3$ & 3.5 & 0.163 & 0 & $1.46 \mathrm{E}+05$ & 0.2 \\
& & & & 20 & $6.01 \mathrm{E}+04$ & 1.2 \\
& & & & 30 & $5.73 \mathrm{E}+04$ & 1.6 \\
\hline
\end{tabular}

\section{SUMMARY}

The SBSMT technique was successfully extended to tubular-shaped Alloy 617 specimens with internal pressurization capability for the evaluation of the effect of primary pressure load on SMT CF properties at $950^{\circ} \mathrm{C}$. The primary load was introduced by internal pressurization. SMT failure data were generated with elastic follow-up factors of 2, 3.5, and 6 and with internal pressures of $0.01 \mathrm{MPa}(2 \mathrm{psi})$ and $1.03 \mathrm{MPa}(150 \mathrm{psi})$ at intermediate strain ranges. The results show that, although $150 \mathrm{psi}$ internal pressure is within the allowable pressure limit, the SMT CF cycles to failure were reduced by $60 \%$ and $70 \%$ for the cases tested. The EPP strain range analysis in the EPP+SMT evaluation procedure (Barua et al., 2020) captured the effect of internal pressure. Additional experimental data are needed at different test temperatures to verify the EPP strain range analysis.

Analysis was performed to evaluate the hold time effect on SMT CF life cycles for Alloy617. Lack of test data at high cycle and low strain range region results in major uncertainty in determining the EPP+SMT $\mathrm{CF}$ design curves. Experiments on Alloy 617 were designed and started at $950^{\circ} \mathrm{C}$ to fill in the gap to support the development of SMT-based design curves. 


\section{REFERENCES}

ASMT E2714, "Standard Test Method for Creep-Fatigue Testing”, ASTM International, West Conshohocken, PA.

ASTM-E606, “Standard Test Method for Strain-Controlled Fatigue Testing”, ASTM International, West Conshohocken, PA.

Barua, B, Messner, M.C., and Sham, T.-L. (2020), "Preliminary description of a new creep-fatigue design method that reduces over conservatism and simplifies the high temperature design process" ANL-ART194, Argonne National Laboratory, Lemont, IL.

Messner, M. C., Sham, T. L., Wang, Y., and R. I. Jetter, R.I. (2018), “Evaluation of methods to determine strain ranges for use in SMT design curves”, ANL-ART-138, Argonne National Laboratory, Lemont, IL.

McMurtrey, M.D. and Simpson, J. (2020), "Single-Bar SMT Testing on Alloy 617 using Software

Controls”, INL/EXT-20-59163, Idaho National Laboratory, Idaho Falls, ID.

Wang, Y., Jetter, R. I., Krishnan, K., and Sham, T.-L (2013) "Progress Report on Creep-Fatigue Design Method Development Based on SMT Approach for Alloy 617”, ORNL/TM-2013/349, Oak Ridge National Laboratory, Oak Ridge, TN.

Wang, Y., Jetter, R. I. and Sham, T.-L (2014), “Application of Combined Sustained and Cyclic Loading Test Results to Alloy 617 Elevated Temperature Design Criteria”, ORNL/TM-2014/294, Oak Ridge National Laboratory, Oak Ridge, TN.

Wang, Y., Jetter, R. I., Baird, S. T., Pu, C. and Sham, T.-L. (2015), “Report on FY15 Two-Bar Thermal Ratcheting Test Results”, ORNL/TM-2015/284, Oak Ridge National Laboratory, Oak Ridge, TN.

Wang, Y., Jetter, R. I., and Sham, T.-L. (2016a), "FY16 Progress Report on Test Results In Support Of Integrated EPP and SMT Design Methods Development" ORNL/TM-2016/330, Oak Ridge National Laboratory, Oak Ridge, TN.

Wang, Y., Jetter, R. I., and Sham, T.-L. (2016b), "Preliminary Test Results in Support of Integrated EPP and SMT Design Methods Development”, ORNL/TM-2016/76, Oak Ridge National Laboratory, Oak Ridge, TN.

Wang, Y., Jetter, R.I., and Sham, T.-L. (2017a), "Report on FY17 Testing in Support of Integrated EPPSMT Design Methods Development”, ORNL/TM-2017/351, Oak Ridge National Laboratory, Oak Ridge, TN.

Wang, Y., Jetter, and Sham, T.-L. (2017b), "Pressurized Creep-Fatigue Testing of Alloy 617 Using Simplified Model Test Method", Proceedings of the ASME 2017 Pressure Vessels and Piping Conference, PVP2017-65457, American Society of Mechanical Engineers, New York, NY.

Wang, Y., Jetter, R. I., Messner, M., Mohanty, S., and Sham, T.-L. (2017c), “Combined Load and Displacement Controlled Testing to Support Development of Simplified Component Design Rules for Elevated Temperature Service”, Proceedings of the ASME 2017 Pressure Vessels and Piping Conference, PVP2017-65455, American Society of Mechanical Engineers, New York, NY. 
Wang, Y., Jetter, R. I., Messner, M., and Sham, T.-L. (2018), "Report on FY18 Testing Results in Support of Integrated EPP-SMT Design Methods Development”, ORNL/TM-2018/887, Oak Ridge National Laboratory, Oak Ridge, TN.

Wang, Y., Jetter, R. I., Messner, M., and Sham, T.-L. (2019), “ Development of Simplified Model Test Method for Creep-fatigue Evaluation”, Proceedings of the ASME 2019 Pressure Vessels and Piping Conference, PVP2019-93648, American Society of Mechanical Engineers, New York, NY. 